\title{
Modeling the Curb Parking Price in Urban Center District of China Using TSM-RAM Approach
}

\author{
Yan Wan $\left(\mathbb{D},{ }^{1,2}\right.$ Jibiao Zhou $\mathbb{D}^{3,},{ }^{3,4}$ Wenqiang $\mathrm{He}\left(\mathbb{D},{ }^{1}\right.$ and Changxi Ma ${ }^{5}{ }^{5}$ \\ ${ }^{1}$ School of Civil and Transportation Engineering, Ningbo University of Technology, Ningbo 315211, China \\ ${ }^{2}$ Universität Duisburg-Essen, Duisburg 47057, Germany \\ ${ }^{3}$ Department of Transportation Engineering, Tongji University, Shanghai 201804, China \\ ${ }^{4}$ Intelligent Transport System (ITS) R \& D Center, Shanghai Urban Construction Design and Research Institute (Group) Co., Ltd., \\ Shanghai 201804, China \\ ${ }^{5}$ School of Traffic and Transportation, Lanzhou Jiaotong University, Lanzhou 730070, China
}

Correspondence should be addressed to Jibiao Zhou; zhoujibiao@tongji.edu.cn and Changxi Ma; machangxi@mail.lzjtu.cn

Received 8 December 2019; Revised 16 June 2020; Accepted 23 June 2020; Published 17 July 2020

Academic Editor: Zhigang Xu

Copyright (c) 2020 Yan Wan et al. This is an open access article distributed under the Creative Commons Attribution License, which permits unrestricted use, distribution, and reproduction in any medium, provided the original work is properly cited.

Parking demand forecasting is an important part of urban parking planning and is also an important basis for the development of parking facilities. The primary objective of this study was to explore multiple factors that affect the curb parking price $(\mathrm{CPP})$ and the changing rules of the curb parking price (CPP) with these factors and to predict the CPP in terms of urban mobility. The data were collected through a statistical survey that was administered in 81 cities in China. The cities were divided into three categories: rich cities (RCs), poor cities (PCs), and tourist cities (TCs). Both the time series method (TSM) and regression analysis method (RAM) were developed to simultaneously examine the factors associated with the CPP among parking users. The results showed that TSM and RAM can account for common urban curb parking prices. The prediction results showed that the CPP is affected by the number of urban dwellers (UD), the prevalence of car ownership (CO), and the per capita disposable income (PCDI) of urban residents; the CPP can be predicted by a model built on the basis of the above three influencing factors. The results can enhance our understanding of the factors that affect CPP. Based on the results, some suggestions regarding the use of the CPP range in parking policy planning were discussed.

\section{Introduction}

Curb parking is a public resource [1]. At present, the average ratio of cars to parking spaces in the entire urban district of large cities in China is approximately $1: 0.8$; compared with the ratio of $1: 1.3$ in developed countries, the proportion is seriously low, and the national parking space shortfall is of more than 50 million spaces [2]. For example, there are 5.64 million vehicles in Beijing but only 1.93 million parking spaces; an average of 2.92 vehicles share each parking space, and the parking space gap is 3.71 million [2]. The number of cars in Shenzhen is 3.22 million, and the total number of parking spaces is 1.11 million. An average of 2.90 vehicles share each parking space, and the parking space gap is 2.11 million [2]. Although the number of motor vehicles in
Shanghai is only 3.59 million, less than $60 \%$ that of Beijing, the total number of parking spaces is only 600,000 , and an average of 5.98 vehicles are allocated to one parking space. [2]. Since people are more likely to travel by private motor cars, road traffic congestion is becoming increasingly serious due to the imbalance between parking supply and demand. Statistical data show $[3,4]$ that the search time for a curb parking space in CBDs (central business districts) accounts for $40 \%$ of the total travel time, which also proves that the lack of parking spaces aggravates road congestion to some extent.

Given the current grim parking situation in Chinese cities such as Beijing, Shanghai, and Shenzhen, the government has put forward restrictive measures to address the imbalance between parking supply and demand. For 
example, Beijing has used the experience of Japan and other countries to predict the increase in the number of parking places, but this has not been effective. Many cities have strict parking rules, but violations continue, and the expected effect of the policy has not been achieved [5]. Research on intelligent parking systems has focused on parking induction and berth prediction for more than ten years [6] but has been unable to effectively address the imbalance of parking supply and demand. To alleviate the negative impact of parking problems, a common method is to induce adaptation to parking supply by reducing parking demand, and controlling the parking price is an effective means of adjusting the balance between the two [7]. In many cities in the UK, parking management measures are often combined with changes in parking prices [8-10]. Drivers are more sensitive to changes in the curb parking price (CPP) than to changes in public transportation or fuel prices because it represents a direct user cost [11]. A CPP that is too low or too high can make parking demand unreasonable in terms of the spatial distribution, leading drivers to spend a great deal of time searching for available parking spaces [12-14]. Therefore, CPP management can be used as a parking management policy to reduce parking problems in certain areas $[15,16]$. Furthermore, if the CPP in some areas can be predicted, it will provide references for the formulation and implementation of parking policies.

The current research on the curb parking pricing (CPP) mostly uses discrete selection models, game theory, nonlinear decision analysis models, and other methods to evaluate the rationality of on-street parking pricing, while there are few studies on the curb parking pricing (CPP) prediction. The independent predictors selected by the above model are less predictable and are only applicable to the status quo evaluation. Therefore, it is difficult to help policy makers have a clearer understanding of the city's curb parking prices (CPP) in the future years before formulating relevant policies, which is likely to cause short-sightedness and irrationality of parking policies.

To fill this gap, we propose a mixed forecast method for curb parking price forecasting, combining the time series method (TSM) and regression analysis method (RAM). By collecting historical parking prices, we can predict the future CPP for the core areas of Ningbo, Yancheng, and Kunming. Finally, the practical application shows that the forecast method can be applied to other cities in China. This prediction of the curb parking price can help decision makers develop better parking strategies to balance parking supply and demand and thoroughly solve the problem of urban parking.

This research makes the following three contributions. First, we develop a curb parking price model that combines the TSM approach and RAM approach, using historical data on the number of urban dwellers (UD), car ownership (CO), and per capita disposable income (PCDI) of urban residents to estimate the $2 \mathrm{~h}$ CPP in the core city for the next year. Second, we divide China's cities into the rich cities (RCs), poor cities (PCs), and tourist cities (TCs) and analyze the CPP for the cities under different scenarios. Third, we classify the prediction results for the future year as optimistic, aggressive, or conservative to ensure the accuracy of the outcomes.

The remainder of this paper is organized as follows. Section 2 reviews existing studies on the TSM and the RAM. Section 3 details the data collection method. Section 4 introduces the urban curb parking pricing model, including the model assumptions, construction, and testing. Section 5 describes an application of the curb parking pricing (CPP) model. Section 6 presents the prediction results of the model. Section 7 discusses the results obtained and draws conclusions.

\section{Literature Review}

2.1. Time Series Method Analysis. The time series method (TSM) is a method for establishing mathematical models based on time series data obtained by systematic observation. It is generally performed using curve fitting and parameter estimation methods (i.e., nonlinear least squares) and is widely used in the fields of economics [17], geography [18], and electrical engineering [19].

In economics, Zhu [20] used the seasonal time series model to analyze the compensation data of China's insurance industry from January 2002 to November 2008 and established the Box-Jenkins seasonal model. The results show that the model offers good prediction results, which can provide a reference for the supervision of and decisions on insurance payments in China. While the prediction error increases as the forecast period is extended, data can be continuously added to achieve dynamic prediction after the model is built, which maintains high prediction accuracy. Rabindra and Nirash [21] examined the interrelationships between energy consumption, output, and carbon emissions in a developing economy using an augmented vector autoregression model. Time series data for the period 1975-2013 in Nepal were studied using the population and gross fixed capital formation as additional variables. The authors found that the government of Nepal can address energy poverty by accelerating the adoption of energy conservation policies such as rationing energy consumption and energy efficiency improvements to narrow the energy supply-demand gap. The results remained robust across different estimators and contribute to an emerging literature on the nexus connecting energy consumption, income, and carbon emissions in developing economies.

In the field of geography, Yin et al. [18] assessed the vegetation utilization rate, determined through high-resolution remote sensing inversion, in the Inner Mongolia autonomous region from 1999 to 2009 . The time series analysis method was used to evaluate the desertification development trend with reference to a discussion of the desertification reversal problem. The results showed that the ecological environment in the Inner Mongolia autonomous region had generally improved over the 11 years of the sample period, but the development trend of desertification was not obvious. Reiser and Kutie [22] detected significant trends in the uncertainty of total annual rainfall, the number of rain spells, rain-spell yields, and rainy season length from the time series data of 41 weather stations across the Mediterranean region from 1931 to 2006. In addition, they detected significant temporal changes in the 
occurrence of extreme events on these parameters. The study found that despite the general assumption of tremendous changes in the rainfall regime, there were no significant temporal or uncertainty trends for total annual rainfall, number of rain spells, rain-spell yields, or rainy season length at most of the stations. However, in a few cases, a significant trend was detected.

In electrical engineering, Ding et al. [23] proposed a wind speed prediction model based on time series analysis and used an information criterion to test the model. The results showed that the time series model was suitable for the prediction of wind speeds on wind farms and could reflect future wind speed distribution characteristics. Abdelaal and Algarni [24] used data on monthly domestic electric energy consumption in the eastern province of Saudi Arabia for 5 years to develop autoregressive integrated moving average models and evaluated forecast data for the sixth year. The results showed the optimum ARIMA model forecast monthly data for the evaluation year with an average percentage error of $3.8 \%$, compared to $8.1 \%$ and $5.6 \%$ for the best multiple-series regression and mechanism models, respectively. In other words, the ARIMA model reduced the mean-square forecasting error by factors of 3.2 and 1.6, respectively. Time series analyses in the parking field, on the other hand, have been limited to assessments of the evolution of the number of parking places, and there has been little attention paid to the exploration of parking prices.

2.2. Regression Analysis Method. Since the regression analysis method (RAM) is simpler and more convenient for analyzing multifactor models, its application in many fields, such as mathematics [25], chemistry [26], computer science and technology [27], medicine [28], and other fields, is quite mature, and the results of such analysis can be accurate. The RAM can measure the degree of correlation between various factors and the goodness of fit of the regression.

In the field of mathematics, Lin et al. [29] discussed the estimation and testing of unknown parameters in multiple linear regression models and offered an example thereof. The study found that the accuracy and reliability of the recorded data and anomalies in the data set affect the predictive analysis of the dependent variable. Val et al. [30] evaluated the gait parameters and activity of 87 healthy subjects between the ages of 21 and 84, and they constructed a model of each gait parameter and activity measure by regression analysis. The results showed that normalizing gait parameters and activity metrics through a linear regression model can enhance the ability to compare objects with different anthropometric values.

In the chemistry field, Yu et al. [31] used near-infrared spectral data of water molecules to establish a support vector regression model for moisture content. The study found that the predicted root mean-square error of the set of support vector regression models was $2.930 \%$, the correlation coefficient was 0.994 , and the relative analysis error was 9.473 . Kaneko et al. [32] combined independent component analysis and regression analysis methods to extract the significant components, verified the superiority of ICA-MLR (multiple linear regression) over partial least squares with simulation data, and tried to apply this method to a quantitative structure-property relationship analysis of aqueous solubility. The results showed that ICA-MLR achieved higher predictive accuracy than PLS. The study also found that ICA-MLR could extract the effective components from explanatory variables and construct the regression.

In the computer science field, Liu et al. [33] established a linear regression model between TPC-C server performance and the hardware index by using the mathematical statistics method after analyzing various factors affecting the performance of TPC-C. The basic data of the model were derived from the TPC-C server test results from 2008 to 2013. The results showed that the optimized model estimation accuracy was over $95 \%$ and could explain the causal relationship between the hardware index of the server and TPCC performance to a certain extent. Peng et al. [34] extracted residual images by using multiple linear regressions to discriminate between natural images and computer-generated graphics and then investigated the fitting degree of the regression model. Experimental results and analysis show that it can achieve an average identification accuracy of 98.69\%, and it is robust against JPEG compression, rotation, additive noise, and image resizing.

In the medical field, $\mathrm{Ma}$ et al. [35] performed multiple linear regression analysis of X-ray measurements and WOMAC scores of knee osteoarthritis and analyzed their relationship with clinical and biomechanical concepts. The results showed the statistical significance of AP X-ray values and WOMAC scores $(P<0.05)$ but no statistical significance of lateral X-ray values and WOMAC scores $(P>0.05)$. Kondo et al. [36] proposed a logistic group method of data handling (GMDH)-type neural network and applied it to medical image diagnostics for lung cancer, using principal component-regression analysis to estimate the parameters of the neural network. The identification results show that the logistic GMDH-type neural network algorithm is useful for medical image diagnostics for lung cancer since the optimum neural network architecture is automatically organized to fit the complexity of the medical images.

Turning our attention to our research setting, we note that parking prices are actually related to a number of external factors [37], and the RAM approach is easier to analyze multifactor models; hence, the RAM approach can also be applied in the field of parking prices. In related research, Kelly and Clinch [38] used questionnaires to investigate the difference in price sensitivity between trips made for business purposes and those made for nonbusiness purposes. Ordered probit regression analysis was used on survey responses from travelers who used parking spaces to a series of suggested increases in localized on-street parking tariffs. The results showed a progressively widening gap in price sensitivity as the suggested parking prices increased. The results highlighted that the potentially varied impact of pricing measures on specific subsets of the market are often overlooked in the policymaking process. Albalate and Gragera [39] explored the determinants of garage prices by drawing on a new self-constructed database for all garages in the city of Barcelona. The results indicated that prices are mainly influenced by drivers' fixed and variable costs, the dominant 
position of the garage in its surrounding market and the garage's interaction with curbside parking. The study also found that the garage prices react to the scarcity of street parking spaces and to the curbside price fixed by the public authority. Kobus et al. [40] introduced probabilistic regression analysis to estimate the effect of parking prices on car drivers' choice between street and garage parking. The methodology was applied to daytime parking data for an area where cruising for parking is absent, street parking is ubiquitous, and garage parking is discretely located over space. The study found that drivers were willing to pay a premium for street parking that ranged from $€ 0.37$ to $€ 0.60$, and the demand for street parking was price elastic. The results showed that even small reductions in street parking prices induced a strong increase in the stock of cars parked on-street, and a policy that imposed a premium on-street parking reduced the total number of parking places. The curb parking prices (CPP) are largely a manifestation of the relationship between parking supply and demand. Increasing parking supply will induce higher parking demand, which will lead to a vicious circle; increasing parking prices can increase parking supply while suppressing parking demand. Therefore, the study of curb parking prices (CPP) is actually to solve the problem of parking demand, such as parking turnover rate and parking duration.

In order to explore multiple factors that affect the curb parking price (CPP) and the changing rules of the CPP with these factors and to predict the CPP in terms of urban mobility, this article reviews the domestic and foreign research related to time series and regression analysis. From the analysis results of the literature review, time series methods and regression analysis methods can be used to achieve the purpose of this article.

\section{Data Collection}

It should be noted that the number of urban dwellers (UD), the prevalence of car ownership (CO), and per capita disposable income (PCDI) are macrolevel influencing factors of curb parking prices. Because the topic of this study is mainly curb parking prices in urban core areas, the spatial scope is relatively wide, and the degree of influence of microlevel factors such as major and minor roads and road length on curb parking prices in the sample area is assumed to be relatively negligible.

The basic data of the article come from the China Statistical Yearbook [2]. The reliability of data sources can be guaranteed. In the process of data source selection, this article compares the national economic and social development statistical bulletins of various cities to avoid potential errors in data sources. Among them, the number of urban dwellers (UD) and per capita disposable income (PCDI) can be directly obtained, while car ownership (CO) needs to be determined through further calculation of the data in statistical yearbooks.

Except for the RCs and PCs, cities can be divided by their PCDI, and the TCs appear in this section in a separate category because of their special urban functions and positioning. Some RCs, such as Suzhou and Xiamen, and PCs, such as Guiyang, need to be attentive to the impact of tourism, which accounts for a large proportion of their gross domestic product (GDP). Therefore, some RCs and PCs can also be classified as TCs.

TCs, for their part, can be considered a city classification between RCs and PCs. This study collects data on the following variables for the core areas of $36 \mathrm{RCs}, 26 \mathrm{PCs}$, and 31 TCs: 2 h CPP, UD, CO, and PCDI. The statistical results are shown from Tables 1 to 3 .

\section{Urban Curb Parking Pricing Model}

4.1. Model Assumptions. The core area of the city is the main part of the urban public activity system. It displays a certain agglomeration effect and is an important place for urban residents to carry out various activities and exchanges. Therefore, the parking problem is an important focus in such areas. The basic hypotheses of the CPP prediction model in this paper are as follows.

4.1.1. The CPP $(Y)$ Has a Clear Relationship with $U D\left(X_{1}\right)$, $\mathrm{CO}\left(X_{2}\right)$, and PCDI $\left(X_{3}\right)$, Which Are Significant at $P \leq 0.05$. The CPP is generally common to entire urban areas. Therefore, the UD and PCDI are selected as the predictor variables. At the same time, the parking prices basically apply only to cars, so CO is selected as another predictor variable. In a study, Humphrey and Swingley [30] took PCDI and motor vehicle ownership as predictor variables, but the study's accuracy has still not been established.

4.1.2. The Three Variables, UD $\left(X_{1}\right), C O\left(X_{2}\right)$, and PCDI $\left(X_{3}\right)$, Increase with Time $(t)$. To obtain the future $2 \mathrm{~h}$ CPP in the core area of the city, it is necessary to calculate UD, CO, and PCDI for the coming years. If UD, CO, and PCDI have an increasing trend in terms of time, future variation in the three parameters can be obtained by using the TSM. Thus, the CPP in the core area of the city can be predicted by means of this method.

4.1.3. The Absolute Values of the Prediction Error of the Three Parameters, UD $\left(X_{1}\right), C O\left(X_{2}\right)$, and PCDI $\left(X_{3}\right)$, Are below 0.05 , i.e., $\Delta \leq 0.05$. The prediction accuracy refers to the degree of density or dispersion in the prediction error distribution, that is, the dispersion between the actual and the corresponding predicted values. If the prediction error $Y_{\mathrm{VC}}$ is small, it indicates that the prediction accuracy is high, and if the prediction error is large, it indicates that the prediction accuracy is low. Therefore, the prediction accuracy values of $\mathrm{UD}, \mathrm{CO}$, and $\mathrm{PCDI}$ are related to the $\mathrm{CPP}$ prediction accuracy. In this paper, an absolute value of the prediction error below 0.05 is considered to be within an acceptable range.

4.2. Parking Pricing Prediction Model Construction. The relationship between $(Y)$ and each of the two variable combinations of the three variable types $\left(X_{1}, X_{2}, X_{3}\right)$ is fitted 
TABLE 1: The curb parking price in the core areas in RCs (2017).

\begin{tabular}{|c|c|c|c|c|}
\hline Cities & 2h CPP (yuan) & UD (10 thousand) & CO (10 thousand) & PCDI (yuan) \\
\hline Beijing & 40 & 1876.6 & 564 & 62406 \\
\hline Shanghai & 70 & 2120.88 & 359 & 62596 \\
\hline Suzhou & 18 & 1068.36 & 355 & 58806 \\
\hline Shenzhen & 21 & 1249.57 & 322 & 52938 \\
\hline Dongguan & 13 & 749.66 & 263 & 42944 \\
\hline Wuhan & 7 & 853.65 & 261 & 43409 \\
\hline Qingdao & 16 & 625.25 & 246 & 50817 \\
\hline Hangzhou & 22 & 727.14 & 244 & 56276 \\
\hline Guangzhou & 32 & 1248.9 & 240 & 55400 \\
\hline Nanjing & 28 & 685.89 & 239 & 54538 \\
\hline Ningbo & 18 & 579.56 & 229 & 55656 \\
\hline Foshan & 18 & 727.11 & 228 & 46849 \\
\hline Changsha & 15 & 614.38 & 217 & 46948 \\
\hline Shenyang & 17 & 668.2 & 210 & 41359 \\
\hline Fuzhou & 16 & 510.5 & 118 & 40973 \\
\hline Xiamen & 28 & 357.3 & 123 & 50019 \\
\hline Dalian & 12 & 417.7 & 140 & 40587 \\
\hline Wenzhou & 18 & 574.68 & 183.2 & 51866 \\
\hline Shaoxing & 16 & 328.2 & 149.52 & 54445 \\
\hline Jiaxing & 20 & 300.31 & 119.51 & 53057 \\
\hline Wuxi & 14 & 498.03 & 176.45 & 52659 \\
\hline Taizhou & 11 & 380.54 & 148.3 & 51374 \\
\hline Changzhou & 12 & 338.7 & 122.8 & 49955 \\
\hline Tianjin & 16 & 1291.11 & 287 & 37022 \\
\hline Harbin & 10 & 463.8 & 162 & 35546 \\
\hline Hefei & 9 & 587.4 & 169.74 & 37972 \\
\hline Nanchang & 10 & 289.78 & 167 & 37575 \\
\hline Wuhu & 9 & 240.42 & 147.68 & 35175 \\
\hline Jinan & 20 & 483.75 & 195 & 46642 \\
\hline Nantong & 9 & 482.4 & 187.3 & 42661 \\
\hline Quanzhou & 7 & 568.3 & 167 & 42696 \\
\hline Tangshan & 14 & 486.8 & 185 & 36415 \\
\hline Yantai & 8 & 451.31 & 187.31 & 41837 \\
\hline Zhuhai & 11 & 157.8 & 88.4 & 46826 \\
\hline Xi'an & 12 & 679.26 & 271 & 38636 \\
\hline Kunming & 16 & 467.7 & 215 & 39788 \\
\hline
\end{tabular}

TABLE 2: The curb parking price in the core areas in PCs (2017).

\begin{tabular}{|c|c|c|c|c|}
\hline Cities & 2h CPP (yuan) & UD (10 thousand) & CO (10 thousand) & PCDI (yuan) \\
\hline Yancheng & 12 & 489.19 & 81.67 & 33115 \\
\hline Xingtai & 3 & 379.12 & 78.63 & 26179 \\
\hline Tieling & 4 & 127.8 & 43.2 & 28337 \\
\hline Liaoyuan & 3 & 59.61 & 12.91 & 30267 \\
\hline Tongliao & 3 & 95.69 & 46.2 & 29667 \\
\hline Lu Liang & 4 & 154.04 & 35.3 & 28704 \\
\hline Zhumadian & 3 & 162.02 & 81.6 & 26340 \\
\hline Linyi & 4 & 305.88 & 105 & 33266 \\
\hline Suzhou & 4 & 66.76 & 44.4 & 32392 \\
\hline Suqian & 3 & 187.5 & 44.85 & 28118 \\
\hline Huanggang & 3 & 234.1 & 43.2 & 26884 \\
\hline Huaihua & 3 & 128.9 & 51.97 & 29498 \\
\hline Hanzhong & 4 & 129.66 & 60.16 & 28812 \\
\hline Guiyang & 6 & 389.19 & 141.4 & 32186 \\
\hline Lanzhou & 8 & 226.05 & 101.7 & 31071 \\
\hline Xining & 5 & 167.53 & 100.1 & 32043 \\
\hline Yinchuan & 4 & 171.56 & 75.88 & 32981 \\
\hline Ganzhou & 5 & 343.38 & 79.86 & 29567 \\
\hline
\end{tabular}


TABLE 2: Continued.

\begin{tabular}{lcccc}
\hline Cities & $2 \mathrm{~h} \mathrm{CPP}($ yuan $)$ & UD $(10$ thousand $)$ & CO (10 thousand) & PCDI (yuan) \\
\hline Taiyuan & 9 & 370.97 & 143.63 & 54.2 \\
Kaifeng & 3 & 215.73 & 104.29 & 29864 \\
Nanning & 6 & 378.44 & 18 & 33217 \\
Jingdezhen & 6 & 109.8 & 59.6 & 34283 \\
Huainan & 4 & 221.29 & 62.1 & 32405 \\
Qinhuangdao & 3 & 180.1 & 83.75 & 32795 \\
Changchun & 7 & 438.3 & 28.9 & 33168 \\
Fushun & 4 & 146 & 30346 \\
\hline
\end{tabular}

in MATLAB, and it was found that all display quadratic curve relationships, as shown in Figures 1-3.

The purpose of the data visualization step was to determine the relationship and trend between the curb parking price (CPP) and the three independent variables to create a theoretical basis for the construction of the parking pricing model.

4.2.1. RAM Model. All the basic data were fitted again, and all three city types showed the highest fit with the quadratic curve. Therefore, the following ternary quadratic function can be established to describe the relationships among $Y, X_{1}$, $X_{2}$, and $X_{3}$ :

$Y=a_{1} X_{1}^{2}+a_{2} X_{2}^{2}+a_{3} X_{3}^{2}+a_{4} X_{1} X_{2}+a_{5} X_{1} X_{3}+a_{6} X_{2} X_{3}+C$, where $a_{1}, a_{2}, \ldots, a_{6}$ are the regression coefficients and $C$ is a constant value.

For convenience, equation (1) was converted to a sixelement linear regression as follows:

$$
Y=a_{1} z_{1}+a_{2} z_{2}+a_{3} z_{3}+a_{4} z_{4}+a_{5} z_{5}+a_{6} z_{6}+C .
$$

The independent variable is changed from the original variables $X_{1}, X_{2}, X_{3}$ to $z_{1}, z_{2}, z_{3}, z_{4}, z_{5}, z_{6}$. $Y$ is output as the dependent variable and $z_{1}, z_{2}, z_{3}, z_{4}, z_{5}, z_{6}$ are input as the independent variables. The CPP models of RC $\left(Y_{\mathrm{RC}}\right), \mathrm{PC}$ $\left(Y_{\mathrm{PC}}\right)$, and $\mathrm{TC}\left(Y_{\mathrm{VC}}\right)$ are obtained as follows:

$$
\begin{aligned}
Y_{\mathrm{RC}}= & 4.2979 * 10^{-5} X_{1}^{2}+9.2284 * 10^{-4} X_{2}^{2}+9.8863 * 10^{-9} X_{3}^{2}-3.7286 * 10^{-4} X_{1} X_{2} \\
& +6.0596 * 10^{-7} X_{1} X_{3}-3.3812 * 10^{-6} X_{2} X_{3}+1.6041, \\
Y_{\mathrm{PC}}= & 1.1069 * 10^{-4} X_{1}^{2}+2.7739 * 10^{-3} X_{2}^{2}+6.2943 * 10^{-9} X_{3}^{2}-8.3403 * 10^{-4} X_{1} X_{2} \\
& +4.9973 * 10^{-7} X_{1} X_{3}-2.1672 * 10^{-6} X_{2} X_{3}-2.3045, \\
Y_{\mathrm{VC}}= & 6.9089 * 10^{-5} X_{1}^{2}+6.6710 * 10^{-4} X_{2}^{2}+7.4237 * 10^{-9} X_{3}^{2}-4.3752 * 10^{-4} X_{1} X_{2} \\
& -1.9094 * 10^{-7} X_{1} X_{3}+7.7826 * 10^{-7} X_{2} X_{3}-2.1381 .
\end{aligned}
$$

4.2.2. TSM Model. A time series is a sequence of successive observations of the same phenomenon at different times. Here, $t$ is used to indicate the time of the observation, $X$ is the observed value, and $X_{i}(i=1,2, \ldots, m)$ is the observed value at time $t_{i}$.

Exponential smoothing is a method of predicting the weighted average of past observations, which makes the predicted value of the $t+1$ period equal to the weighted average of the actual observation value in period $t$ and the predicted value in period $t$. An exponential smoothing method is a special form of a weighted average. At longer observation time horizons, the weight of the index is decreased. The single exponential smoothing method has only one smoothing coefficient and uses the linear combination of the predicted value and the observed value for a period as the predicted value for period $t+1$. The prediction model is as follows:

$$
F_{t+1}=\alpha X_{t}+(1-\alpha) F_{t},
$$

where $R^{2}$ is the predicted value for period $R^{2}, R^{2}$ is the observed value for period $R^{2}$, and $X_{1}$ is the smoothing coefficient $X_{2}$.

It can be seen from the above equation that the predicted value of period $X_{3}$ is a weighted average of the actual observed value in period $t$ and the predicted value in period $t$. At the beginning of the calculation, there is no prediction $F_{1}$ for the first period, so we assume that $F_{1}=X_{1}$.

By analogy, it can be seen that any predicted value $F_{t+1}$ is a weighted average of all previous actual observations. For 
TABLE 3: The curb parking price in the core areas in TCs (2017).

\begin{tabular}{|c|c|c|c|c|}
\hline Cities & $2 \mathrm{~h} \mathrm{CPP} \mathrm{(yuan)}$ & UD (10 thousand) & CO (10 thousand) & PCDI (yuan) \\
\hline Tianjin & 16 & 1291.11 & 287 & 37022 \\
\hline Chengdu & 16 & 1152.81 & 452 & 38918 \\
\hline Kunming & 16 & 467.7 & 215 & 39788 \\
\hline Suzhou & 18 & 1068.36 & 355 & 58806 \\
\hline Zhuhai & 11 & 157.8 & 88.4 & 46826 \\
\hline Yantai & 8 & 451.31 & 187.31 & 41837 \\
\hline Xiamen & 28 & 357.3 & 123 & 50019 \\
\hline Yangzhou & 7 & 197.77 & 67 & 38828 \\
\hline Dalian & 12 & 417.7 & 140 & 40587 \\
\hline Qingdao & 16 & 625.25 & 246 & 50817 \\
\hline Haikou & 16 & 103.95 & 77.25 & 33320 \\
\hline Xi'an & 12 & 679.26 & 271 & 38636 \\
\hline Hangzhou & 22 & 727.14 & 244 & 56276 \\
\hline Shenzhen & 21 & 1249.57 & 322 & 52938 \\
\hline Nanjing & 28 & 685.89 & 239 & 54538 \\
\hline Guangzhou & 32 & 1248.9 & 240 & 55400 \\
\hline Shenyang & 17 & 668.2 & 210 & 41359 \\
\hline Harbin & 10 & 463.8 & 162 & 35546 \\
\hline Changchun & 7 & 438.3 & 143.75 & 33168 \\
\hline Jinan & 20 & 516.36 & 191.1 & 46642 \\
\hline Huangshan & 4 & 70.45 & 18.48 & 30821 \\
\hline Guilin & 5 & 247.34 & 56.15 & 32534 \\
\hline Weihai & 4 & 187.79 & 66.16 & 27898 \\
\hline Qinhuangdao & 3 & 180.1 & 62.1 & 32795 \\
\hline Sanya city & 7 & 443.62 & 112 & 33638 \\
\hline Xianyang & 4 & 219.94 & 83.4 & 34246 \\
\hline Dunhuang & 4 & 12.79 & 10.2 & 31322 \\
\hline Taian & 4 & 342.3 & 69.39 & 32739 \\
\hline Lijiang & 4 & 46.4 & 35.2 & 30403 \\
\hline Jingdezhen & 6 & 109.8 & 18 & 34283 \\
\hline Guiyang & 6 & 389.19 & 131.4 & 32186 \\
\hline
\end{tabular}

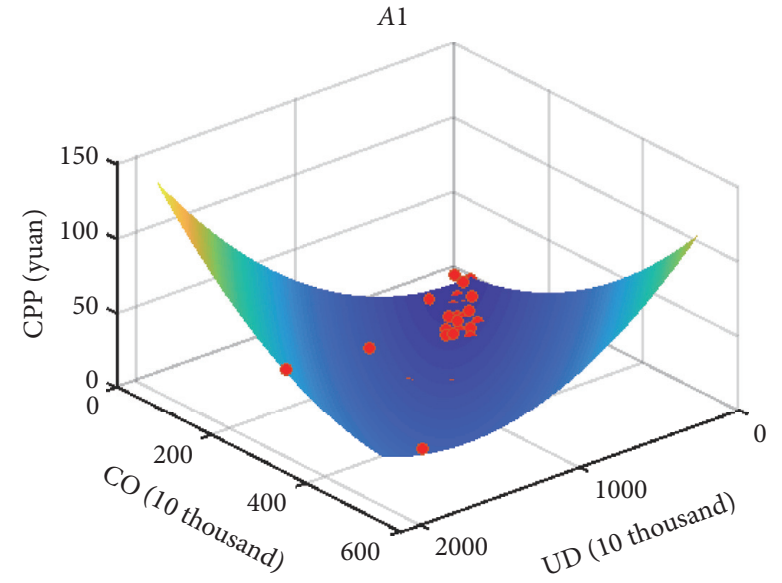

(a)

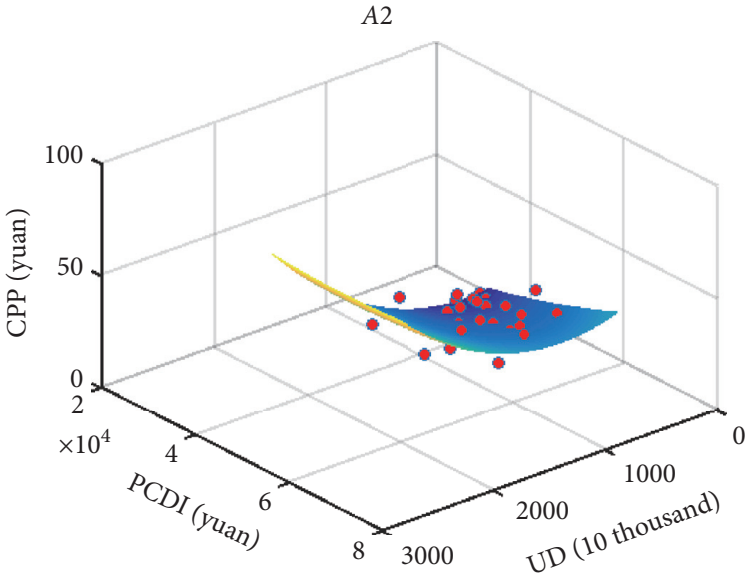

(b)

FIgURE 1: Continued. 


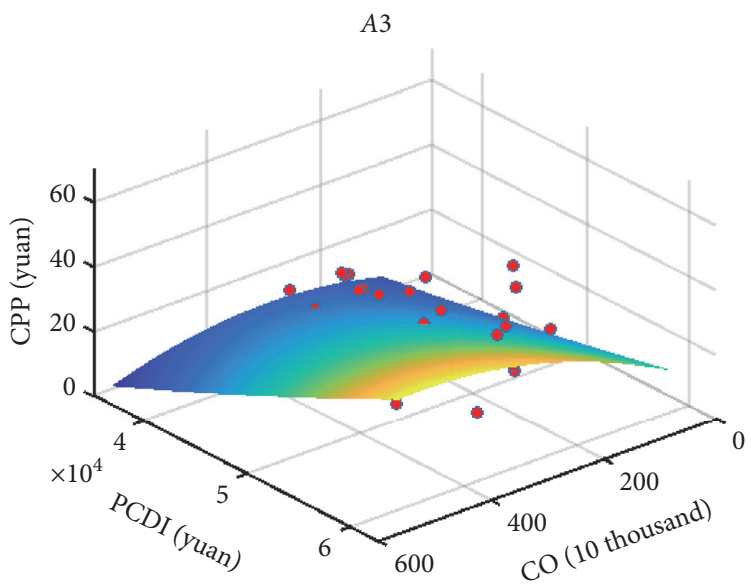

(c)

Figure 1: 3D data visualization for rich cities: (a) the effect among CPP-UD-CO, (b) the effect among CPP-UD-PCDI, and (c) the effect among CPP-CO-PCDI.

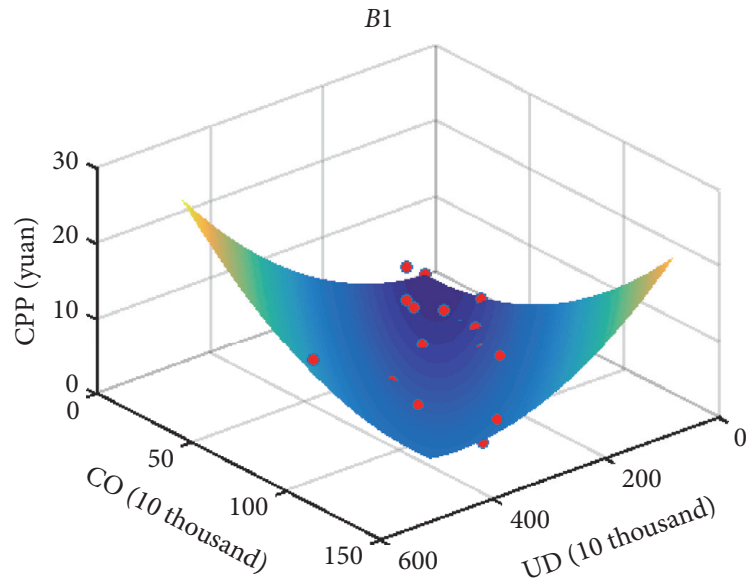

(a)

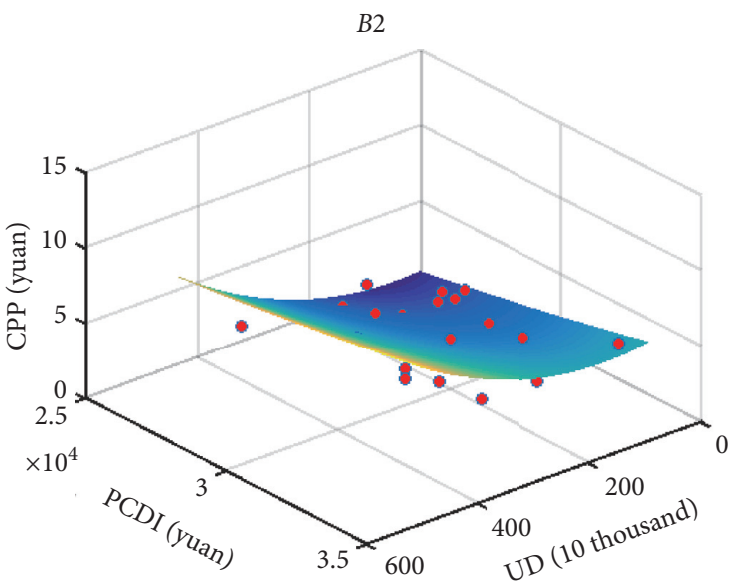

(b)

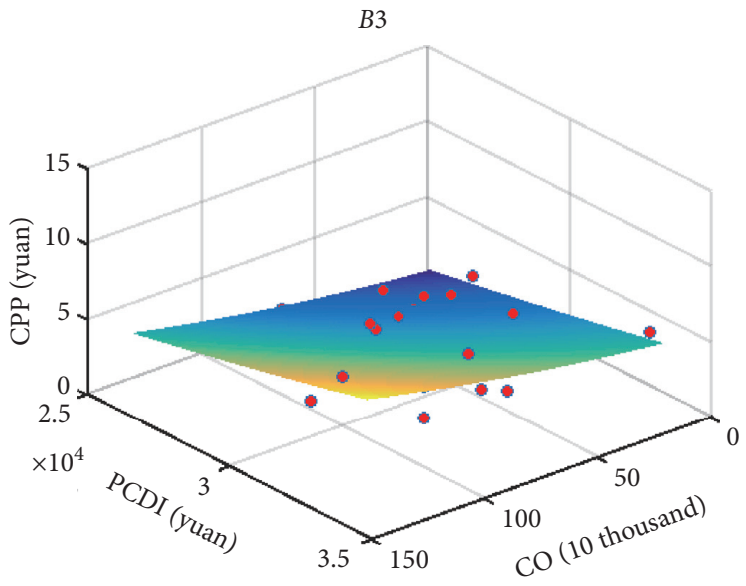

(c)

Figure 2: 3D data visualization for poor cities: (a) the effect among CPP-UD-CO, (b) the effect among CPP-UD-PCDI, and (c) the effect among CPP-CO-PCDI. 


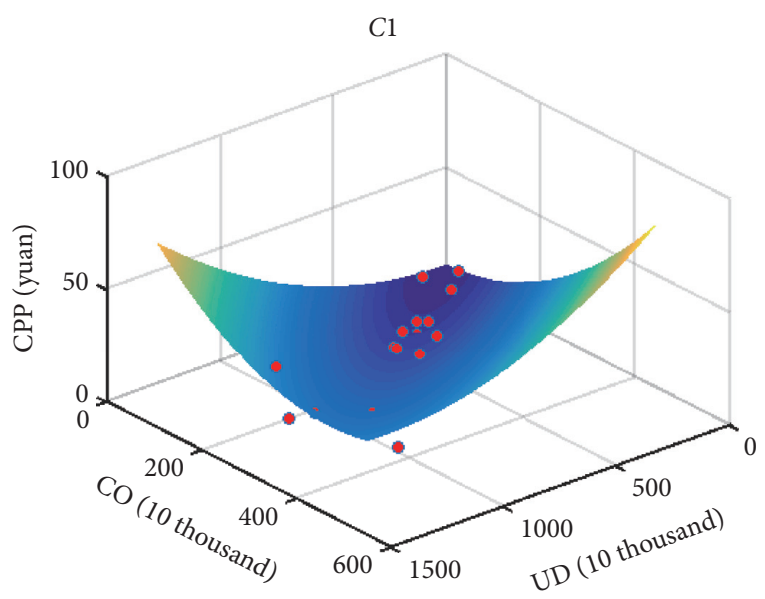

(a)

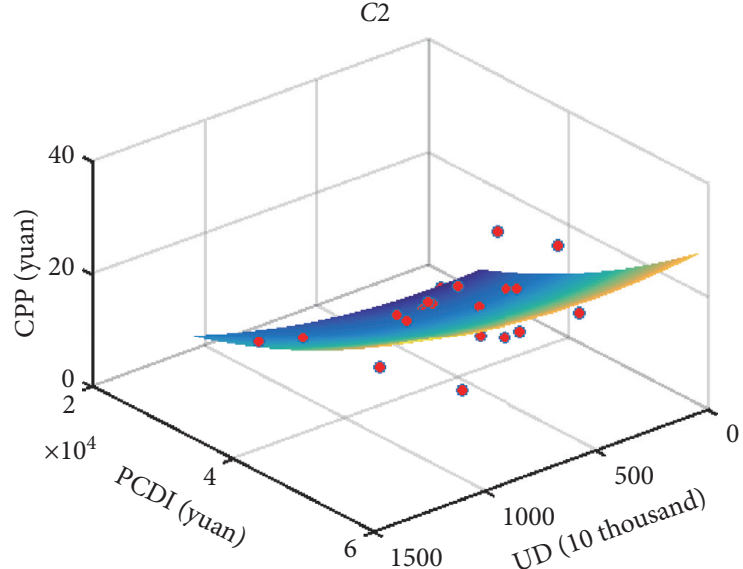

(b)

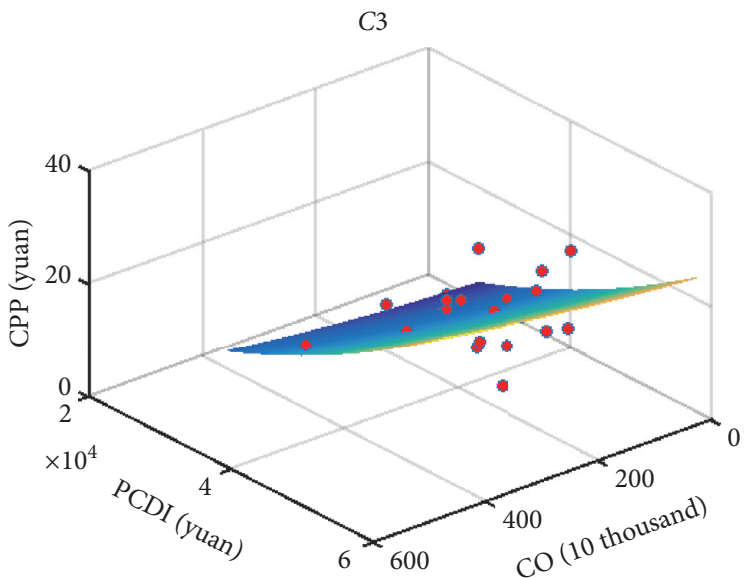

(c)

Figure 3: 3D data visualization for touristed cities: (a) the effect among CPP-UD-CO, (b) the effect among CPP-UD-PCDI, and (c) the effect among CPP- CO-PCDI.

this reason, the formula for exponential smoothing can be written as follows:

$$
\begin{aligned}
F_{t+1} & =\alpha X_{t}+(1-\alpha) F_{t} \\
& =\alpha X_{t}+F_{t}-\alpha F_{t} \\
& =F_{t}+\alpha\left(X_{t}-F_{t}\right) .
\end{aligned}
$$

It can be seen that $F_{t+1}$ is the sum of the predicted value $F_{t}$ of period $t$ and the prediction error $T$.

4.2.3. TSM-RAM Model. According to the above, the combined time series and regression analysis model should be as follows:

$$
\begin{aligned}
Y_{t+1}= & \sum_{t}^{n} a_{n}\left[F_{n t}+\alpha\left(X_{n t}-F_{n t}\right)\right]+C \\
= & a_{1}\left[F_{1 t}+\alpha\left(X_{1 t}-F_{1 t}\right)\right]+a_{2}\left[F_{2 t}+\alpha\left(X_{2 t}-F_{2 t}\right)\right] \\
& +a_{3}\left[F_{3 t}+\alpha\left(X_{3 t}-F_{3 t}\right)\right] \\
& +a_{4}\left[F_{4 t}+\alpha\left(X_{4 t}-F_{4 t}\right)\right]+a_{5}\left[F_{5 t}+\alpha\left(X_{5 t}-F_{5 t}\right)\right] \\
& +a_{6}\left[F_{6 t}+\alpha\left(X_{6 t}-F_{6 t}\right)\right]+C,
\end{aligned}
$$

where $X_{n t}$ is the observed value of $X_{n}$ in period $t, F_{n t}$ is the predicted $X_{n t}$ value in period $t, \alpha$ is the smoothing coefficient $(0<\alpha<1)$, and $n \in(1,2, \ldots, 6)$.

In this paper, the TSM-RAM method is used to calculate the parking price for future years. Due to the higher data frequency of the time series for the independent variables, the time series method is used to calculate the change in the value of the independent variables in future years. At the same time, according to the $3 \mathrm{D}$ data visualization results, the relationship between the parking price and the three independent variables is a quadratic function, so the regression analysis method can be used to estimate the relationship between the independent and dependent variables.

\subsection{Testing the Parking Price Model}

4.3.1. Goodness-of-Fit Test. The $R^{2}$ is the coefficient used to assess the goodness of fit of the regression line with the observations, and its maximum value is 1 . The larger the $R^{2}$ is, the better the fit. In contrast, the smaller the $R^{2}$ is, the worse the fit. 
TABLE 4: Goodness-of-fit test results.

\begin{tabular}{lcccc}
\hline City type & $R$ & $R^{2}$ & Adjusted $R^{2}$ & Standard error \\
\hline RC & 0.9360 & 0.8762 & 0.8505 & 4.4401 \\
PC & 0.9062 & 0.8212 & 0.7647 & 1.1696 \\
TC & 0.8819 & 0.7777 & 0.7221 & 4.2778 \\
\hline
\end{tabular}

TABLE 5: Variance analysis.

\begin{tabular}{lcc}
\hline City type & $F$ & Significance $F$ \\
\hline RC & 34.1967 & 0.0000 \\
PC & 14.5449 & 0.0000 \\
TC & 13.9906 & 0.0000 \\
\hline
\end{tabular}

TABLE 6: Regression coefficient test.

\begin{tabular}{lclll}
\hline City type & Coefficient & Value & $T$ & Significance \\
\hline \multirow{3}{*}{ RC } & $a_{1}$ & $4.2979^{*} 10^{-5}$ & 3.3815 & 0.0021 \\
& $a_{2}$ & $9.2284^{*} 10^{-4}$ & 2.2091 & 0.0352 \\
& $a_{3}$ & $8.8863^{*} 10^{-9}$ & 3.5412 & 0.0014 \\
PC & $a_{1}$ & $1.1069^{*} 10^{-4}$ & 3.9411 & 0.0009 \\
& $a_{2}$ & $1.7739^{*} 10^{-3}$ & 3.5259 & 0.0023 \\
& $a_{3}$ & $6.2943^{*} 10^{-9}$ & 3.1700 & 0.0050 \\
TC & $a_{1}$ & $6.9089^{*} 10^{-5}$ & 2.4022 & 0.0244 \\
& $a_{2}$ & $6.6710^{*} 10^{-4}$ & 2.1513 & 0.0417 \\
\end{tabular}

According to the goodness-of-fit test results, the $R^{2} s$ of the parking price model for RCs, PCs, and TCs are 0.8762 , 0.9050 , and 0.7777 , respectively. This means that the accuracy of UD $\left(X_{1}\right), \mathrm{CO}\left(X_{2}\right)$, and PCDI $\left(X_{3}\right)$ in predicting the $2 \mathrm{~h} \mathrm{CPP}$ in the RCs, PCs, and TCs is $88.14 \%, 90.50 \%$, and $77.53 \%$, respectively, which indicates that the variables selected in this model are accurate and appropriate, as shown in Table 4.

4.3.2. F Test. An F test is used to test whether the variance of the two samples is significantly different. According to the results of a variance analysis after model fitting, the $F$ values of the three types of cities are 34.1967, 14.5449, and 13.9996, as shown in Table 5. The corresponding significance levels are $0.0000,0.0000$, and $0.0000(P<0.05)$. This indicates that the ternary quadratic nonlinear model in equation (1) is appropriate. It also proves that there is a significant relationship between the $2 \mathrm{~h}$ CPP in the RCs, PCs, and TCs and the three explanatory variables.

4.3.3. T-Test. The T-test evaluates the significance of the relationship between the three variables, UD, CO, and PCDI, and the $2 \mathrm{~h}$ CPP. According to the regression results, the significance of $X_{1}, X_{2}$, and $X_{3}$ in the RCs is $0.0017,0.0327$, and 0.0013 , respectively. All of these values are less than the critical value of 0.05 , which indicates that the impact of these three variables on the $2 \mathrm{~h} \mathrm{CPP}$ in the core area of developed cities is significant. Similarly, the significance levels of $X_{1}, T$, and $X_{3}$ in the PCs and TCs are less than the critical value of 0.05 , as shown in Table 6 . Thus, the impact of the three independent variables selected in this paper on the $2 \mathrm{~h} \mathrm{CPP}$ in the core area in PCs and TCs is also significant.

\section{Application}

5.1. Case Study. Ningbo is a subprovincial city with municipalities that have an independent planning status under national social and economic development. It is also the economic center of the Yangtze River Delta and of Zhejiang Province. Since 2000, the city's economy has undergone sustained and rapid growth. The living standards of residents have increased substantially, and the amount of car ownership has also increased year by year. By 2018, it had increased 28-fold in 18 years, resulting in increasing parking pressure. The government is now focusing on how to manage parking demand through parking fees. We take Ningbo as a representative RC and collect data on UD, CO, and PCDI in Ningbo to conduct an empirical analysis of the period from 2000 to 2018.

Yancheng is located in the central part of China's eastern coast, in the central and eastern part of Jiangsu Province in the north wing of the Yangtze River Delta. It is the largest prefecture-level city in Jiangsu Province, with a city area of 17,000 square kilometers. The city is flat and resource-rich. The rivers run north-south and east-west. Constrained by 


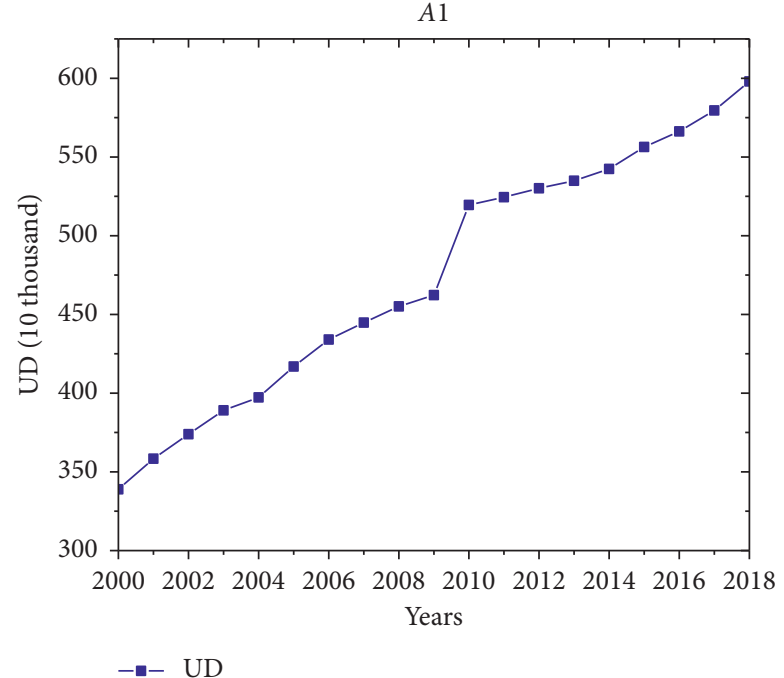

(a)

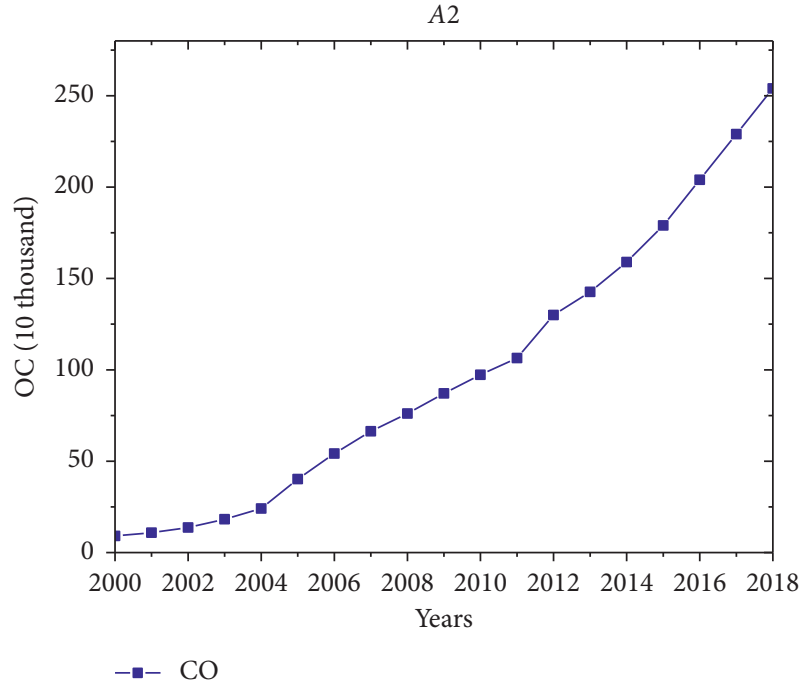

(b)

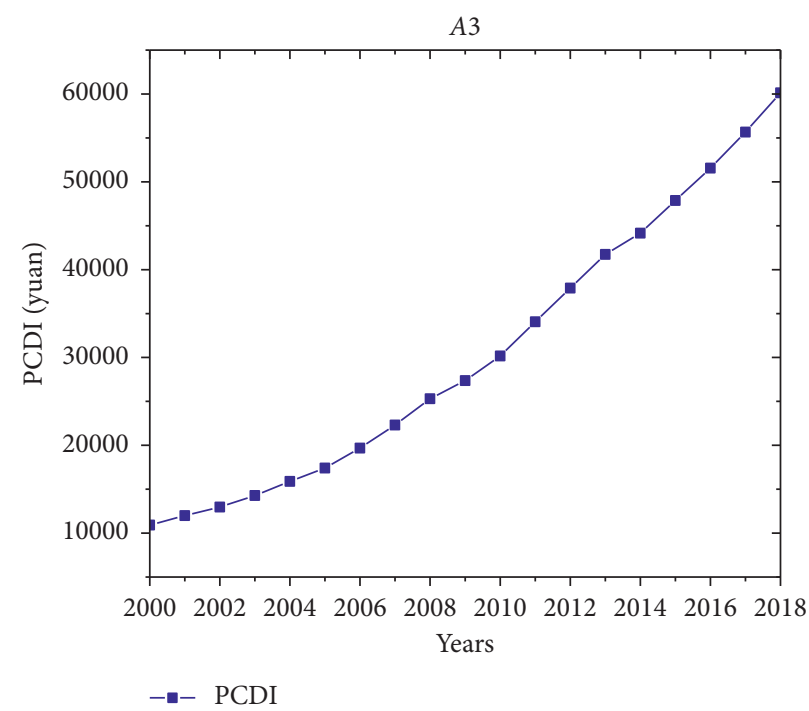

(c)

FIgure 4: Changes in the three data series for Ningbo from 2000 to 2018: (a) changes in the UD historical data, (b) changes in the CO historical data, and (c) changes in the PCDI historical data.

historical conditions, infrastructure, production factors, etc., Yancheng has had a low level of regional economic development for a long time. The problem of high input and low output is obvious. Its car ownership figures fall in the middle to lower levels of the distribution for Jiangsu Province overall, and the development of its parking fees system lags behind that of other provinces. We take Yancheng as a representative $\mathrm{PC}$ and collect $\mathrm{UD}, \mathrm{CO}$, and PCDI data in the city to conduct an empirical analysis of the period from 2000 to 2018 .

Kunming is the capital of Yunnan Province. It is located in the southwestern part of China. It is warm year-round and also known as the "Spring City." Its booming tourism industry has brought enormous opportunities to Kunming. The disposable income and car ownership of urban residents in Kunming can be compared with those of some developed cities. Therefore, parking problems have gradually become an urgent issue in Kunming. We take Kunming as a representative TC and collect $\mathrm{UD}, \mathrm{CO}$, and PCDI data for the city to conduct an empirical analysis of the period from 2000 to 2018.

5.2. Data Processing. We analyze the three data series for each city, as shown in Figures 4-6.

The three data series for Ningbo show an increasing trend over time. Among them, the increasing trends in $\mathrm{CO}$ (Figure 4(b)) and PCDI (Figure 4(c)) are relatively stable; the increasing trend of UD (Figure 4(a)) is stronger in 20092010, resulting from a surge in the migrant population [41]. Overall, the three data series show common characteristics among them. 


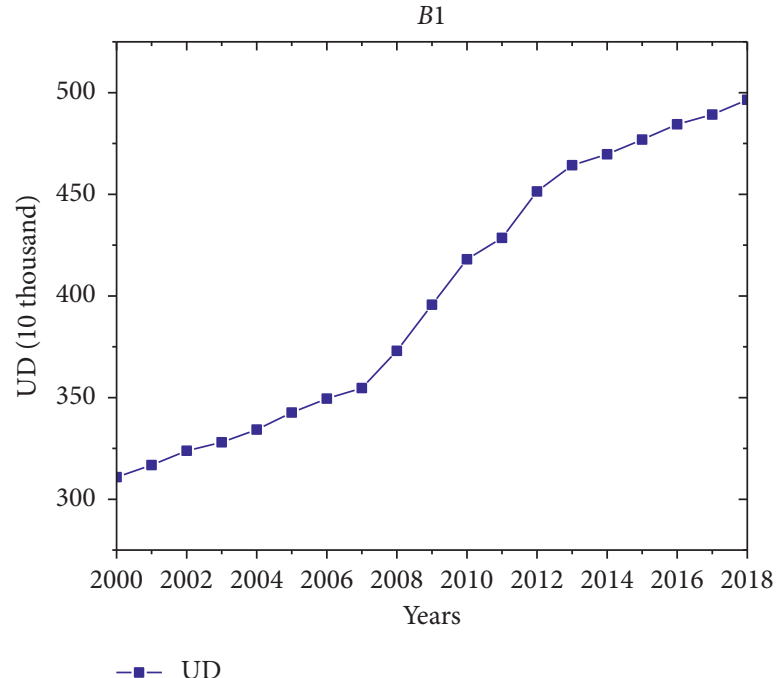

(a)

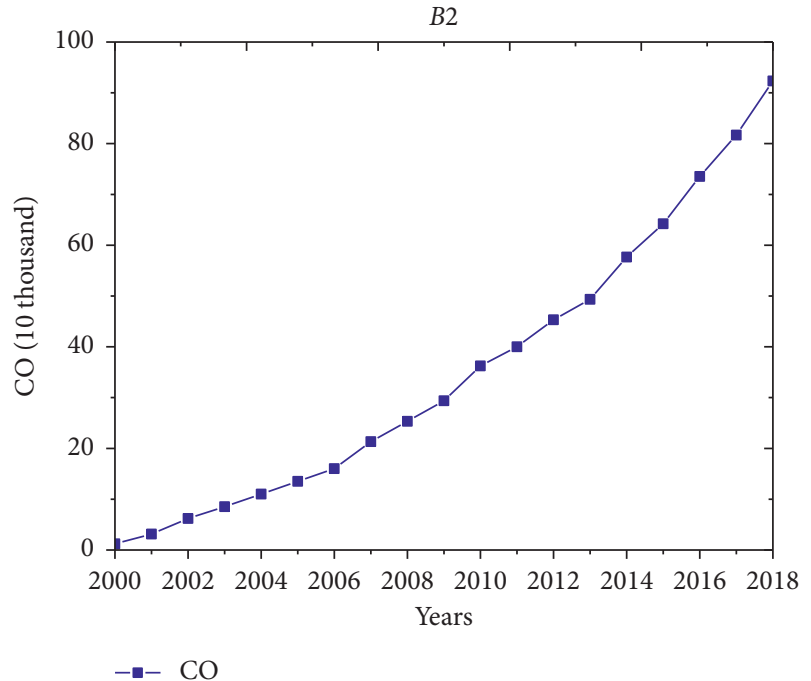

(b)

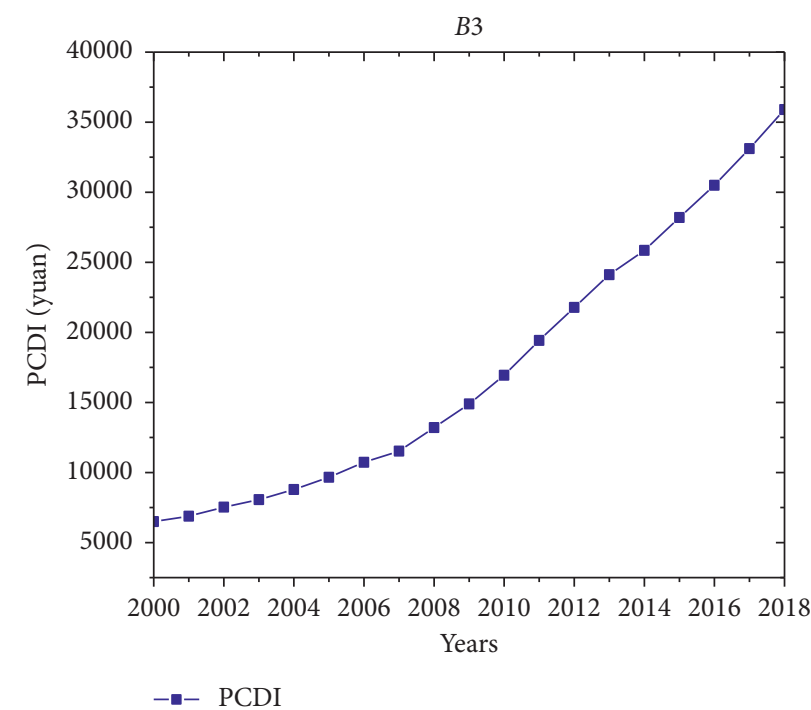

(c)

FIGURE 5: Changes in the three data series for Yancheng from 2000 to 2018: (a) changes in the UD historical data, (b) changes in the CO historical data, and (c) changes in the PCDI historical data.

Yancheng, which has the largest area of a prefecture-level city in Jiangsu Province, China, has a large number of permanent residents, and the proportion of urbanization is relatively low. The growth rate of UD in Yancheng city from 2007 to 2013, which appears in Figure 5(a), is due to the acceleration of urbanization in the city [42]. Correspondingly, the levels of CO (Figure 5(b)) and PCDI (Figure 5(c)) also steadily increase each year. Overall, the UD, CO, and PCDI data series for Yancheng city show common characteristics among them.

The development of tourism has brought enormous economic benefits to Kunming, and its urbanization level exceeded $60 \%$ in 2008 , while the number of permanent urban residents (Figure 6(a)) reached 3 million in 2000 and has maintained a rapid growth trend. Similarly, the improvement of the city's economic level is also reflected in the rapid increase in CO (Figure 6(b)) and PCDI
(Figure 6(c)). Overall, the UD, CO, and PCDI data series for Kunming show common characteristics among them.

\subsection{Parameter Prediction}

5.3.1. Time Series Prediction. The prediction results are divided into optimistic, aggressive, and conservative scenarios. The TSM is used to predict the changes in UD, CO, and PCDI in Ningbo, Yancheng, and Kunming from 2019 to 2021. The statistical results are shown in Table 7, and the overall changes are shown in Figures 7-9. At the same time, the long-term evolution (for 2025 and 2030) of the three data series is also estimated (see Tables 7-9).

The results of the optimistic, aggressive, and conservative estimations of the trends in UD, CO, and PCDI are ordered as follows: aggressive $>$ optimistic $>$ conservative. The changing characteristics of the data confirm the rigor and distinctiveness 


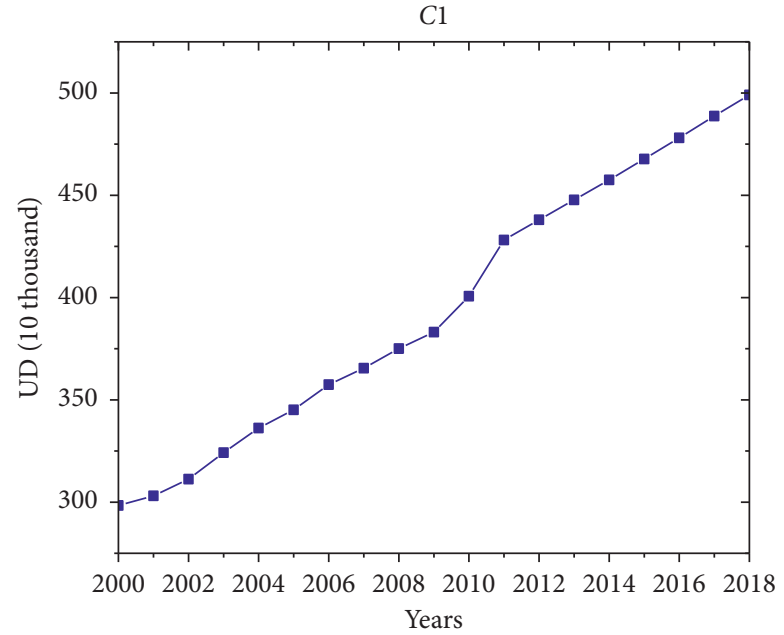

$-\square-\mathrm{UD}$

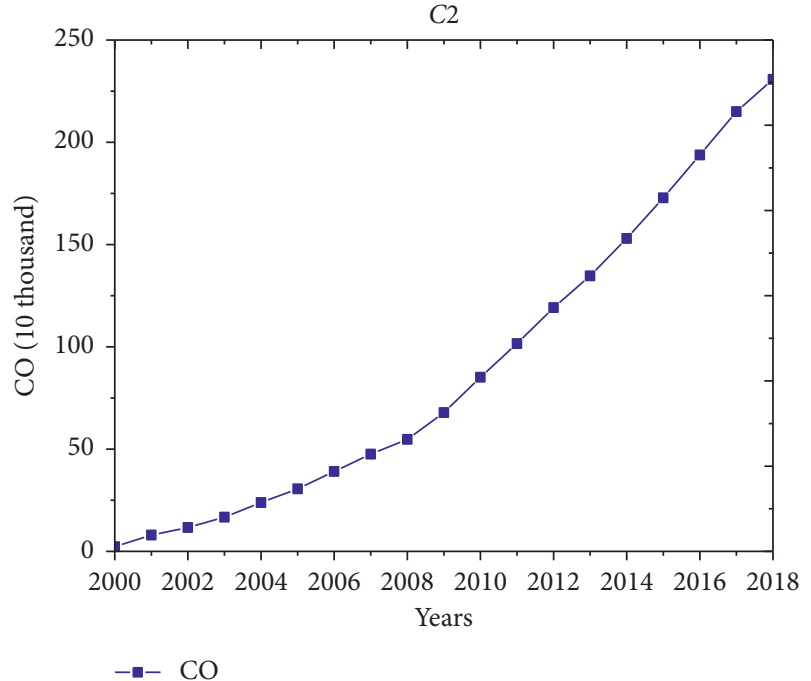

(b)

(a)

C3

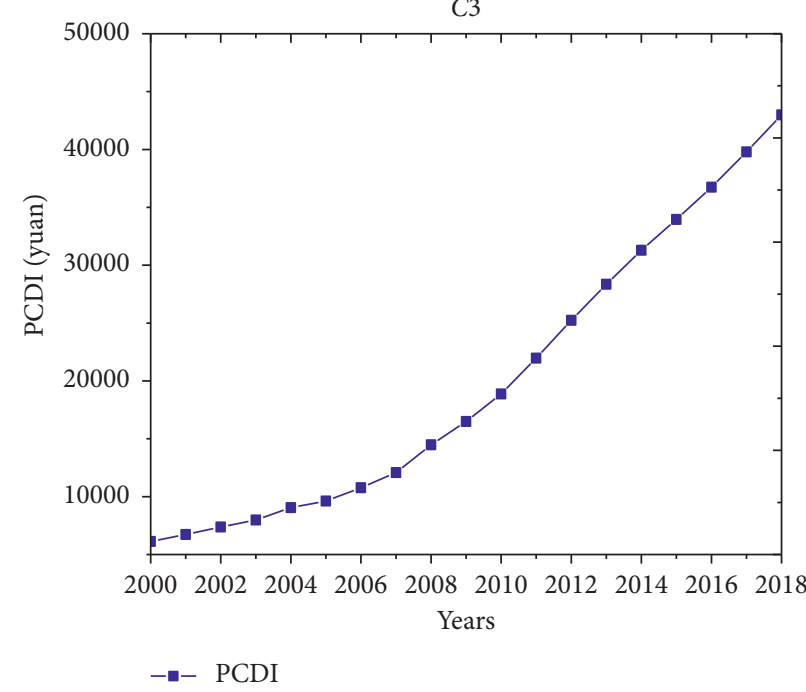

(c)

Figure 6: Changes in the three data series for Kunming from 2000 to 2018: (a) changes in the UD historical data, (b) changes in the CO historical data, and (c) changes in the PCDI historical data.

TABLE 7: Time series prediction for 2019-2021 (optimistic).

\begin{tabular}{|c|c|c|c|c|c|}
\hline Cities & Term & Year & UD (10 thousand) & CO (10 thousand) & PCDI (yuan) \\
\hline \multirow{5}{*}{ NB } & \multirow{3}{*}{ Short-term } & 2019 & 611.19 & 278.87 & 64455 \\
\hline & & 2020 & 625.51 & 303.75 & 68756 \\
\hline & & 2021 & 639.82 & 328.63 & 73097 \\
\hline & \multirow{2}{*}{ Long-term } & 2025 & 698.95 & 428.17 & 90958 \\
\hline & & 2030 & 770.60 & 552.59 & 112977 \\
\hline \multirow{5}{*}{ YC } & \multirow{3}{*}{ Short-term } & 2019 & 503.22 & 101.92 & 38818 \\
\hline & & 2020 & 509.98 & 113.06 & 41880 \\
\hline & & 2021 & 516.73 & 123.84 & 45083 \\
\hline & \multirow{2}{*}{ Long-term } & 2025 & 543.77 & 172.87 & 59303 \\
\hline & & 2030 & 577.56 & 244.09 & 80241 \\
\hline \multirow{5}{*}{ KM } & \multirow{3}{*}{ Short-term } & 2019 & 510.17 & 246.50 & 46341 \\
\hline & & 2020 & 521.31 & 262.25 & 49846 \\
\hline & & 2021 & 532.46 & 278.00 & 53504 \\
\hline & \multirow{2}{*}{ Long-term } & 2025 & 577.05 & 341.00 & 69661 \\
\hline & & 2030 & 632.79 & 419.75 & 93290 \\
\hline
\end{tabular}

Note. NB denotes Ningbo city, YC denotes Yancheng city, and KM denotes Kunming city. 


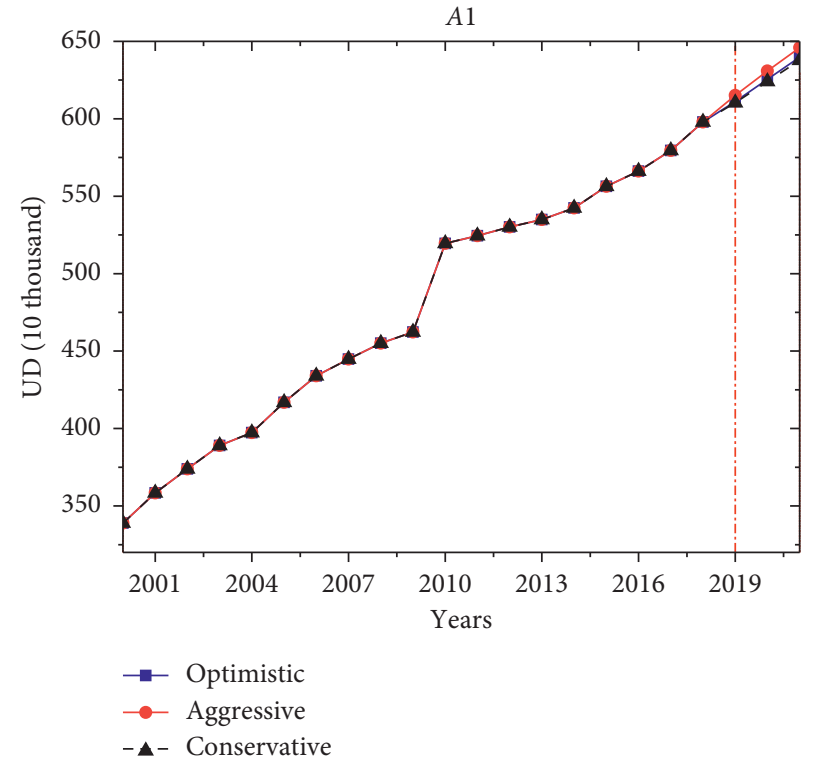

(a)

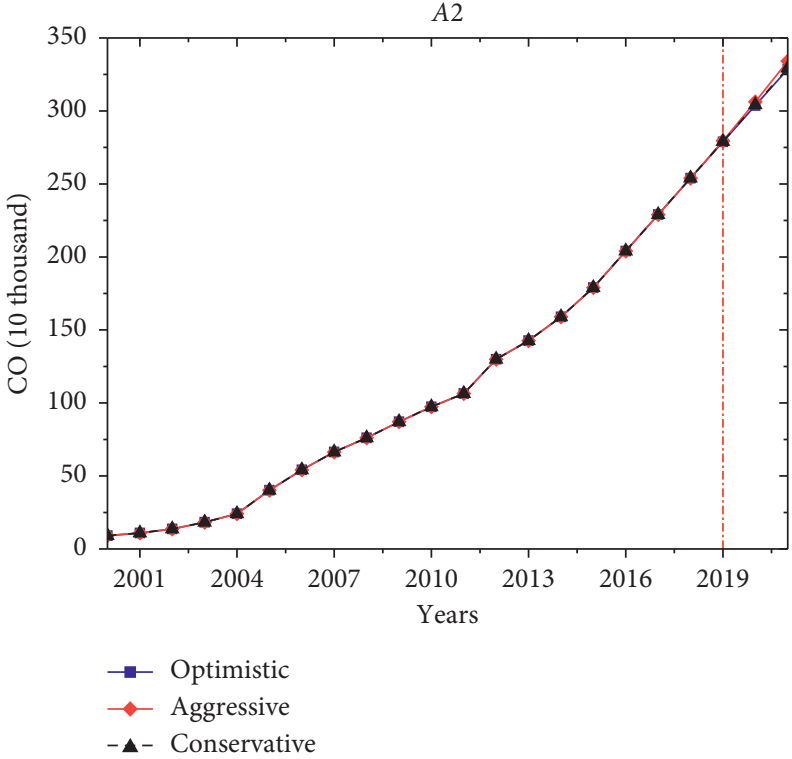

(b)

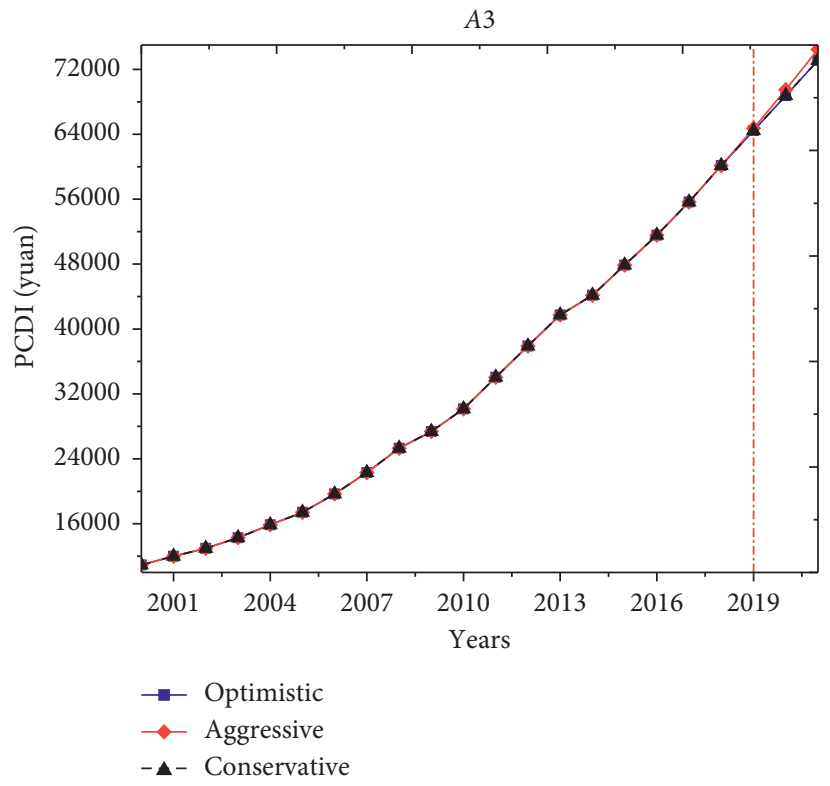

(c)

FiguRE 7: Future changes in the three data series for Ningbo (2019-2021): (a) future changes in UD, (b) future changes in CO, and (c) future changes in PCDI.

of the TSM. The three cities of Ningbo, Yancheng, and Kunming are ordered, in terms of overall economic strength, as follows: Ningbo > Kunming > Yancheng. Moreover, the levels of CO and PCDI in future years in Table 7 are consistent with this ranking. For example, the predicted PCDI for 2030 is 112,977 yuan for Ningbo, 93,290 yuan for Kunming, and 80,241 yuan for Yancheng city. These projections are also consistent with the results of the aggressive and conservative predictions in Tables 8-9.
5.3.2. Error Test. The prediction error refers to the difference between the prediction result and the real result of the development of the predicted variable and is divided into the predicted relative error and the predicted absolute error. The absolute error is the absolute difference between the predicted value and the actual observed value, and the relative error is the percentage difference relative to the observed value. Here, the absolute error is selected to characterize the error of the three data series predicted by the TSM. 


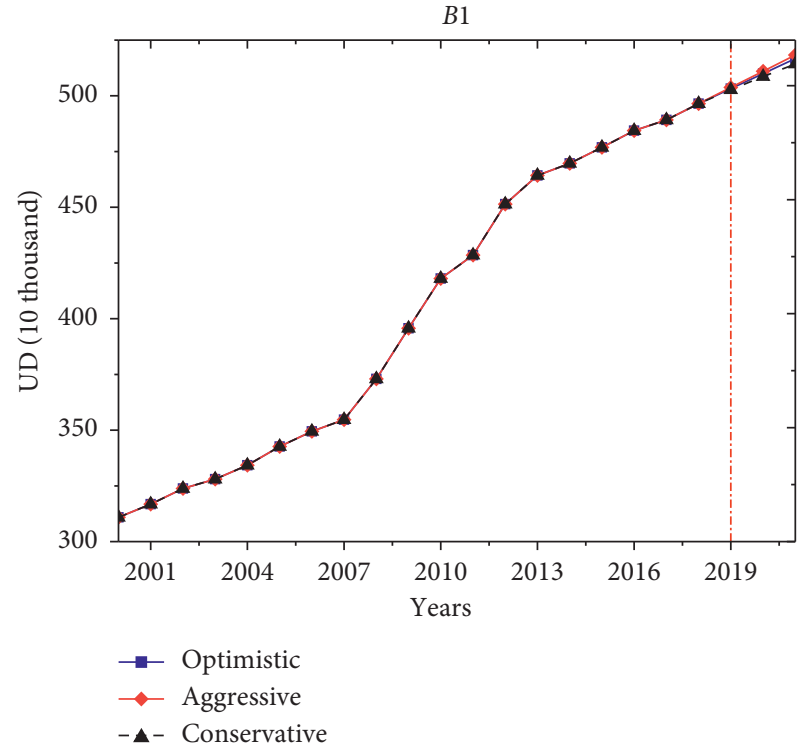

(a)

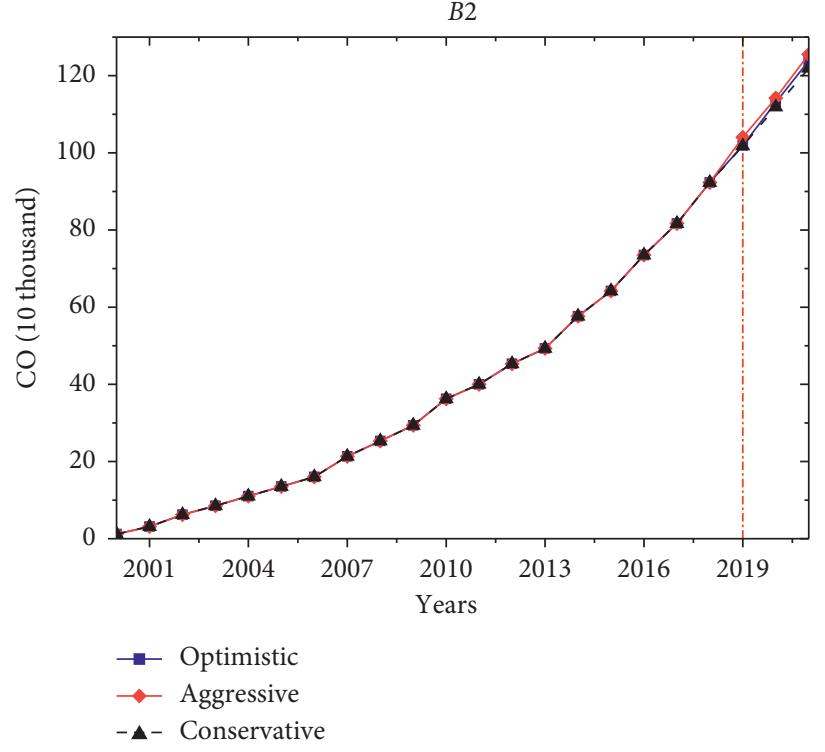

(b)

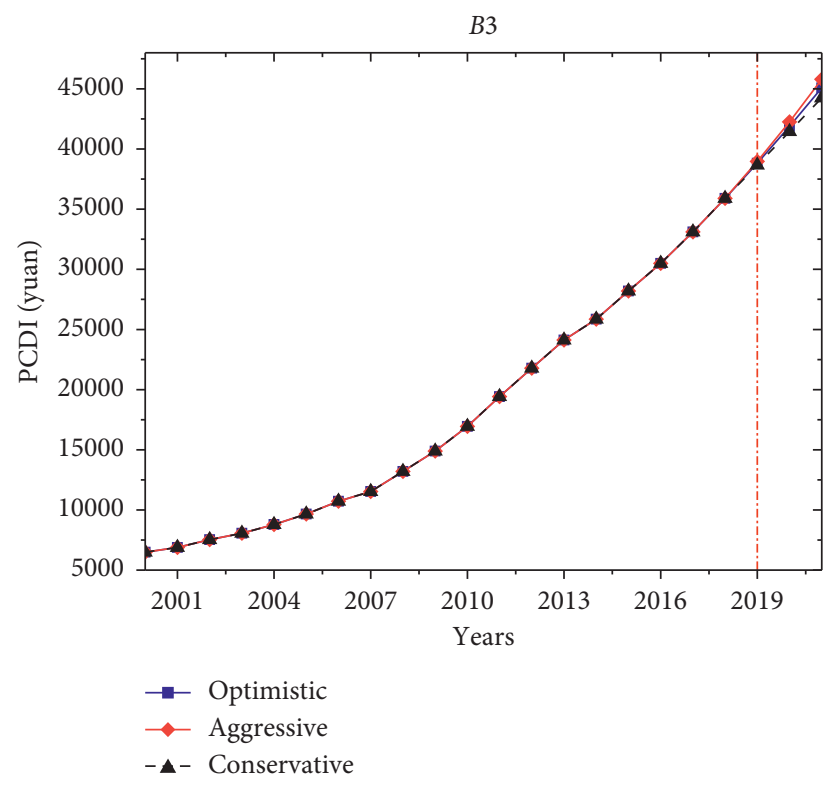

(c)

FIGURE 8: Future changes in the three data series for Yancheng (2019-2021): (a) future changes in UD, (b) future changes in CO, and (c) future changes in PCDI.

Taking 2017 and 2018 as examples, the actual values for the UD, CO, and PCDI series of Ningbo, Yancheng and Kunming are shown in Tables 10-12.

It can be seen from the Tables 11-13 that the three data series estimated by the TSM from 2017 to 2018 for the cities of Ningbo, Yancheng, and Kunming have good results: the maximum error is $3.76 \%$, the minimum error is $0.005 \%$, and the absolute error is below 0.05 (5\%), which is within the acceptable range. At the same time, the average absolute error values of the optimistic, aggressive, and conservative scenarios are $0.532 \%, 1.075 \%$, and $1.080 \%$, respectively-all less than $0.05(5 \%)$.

5.3.3. Goodness-of-Fit Test. According to the test results, the goodness of fit of the TSM for the optimistic, aggressive, and 


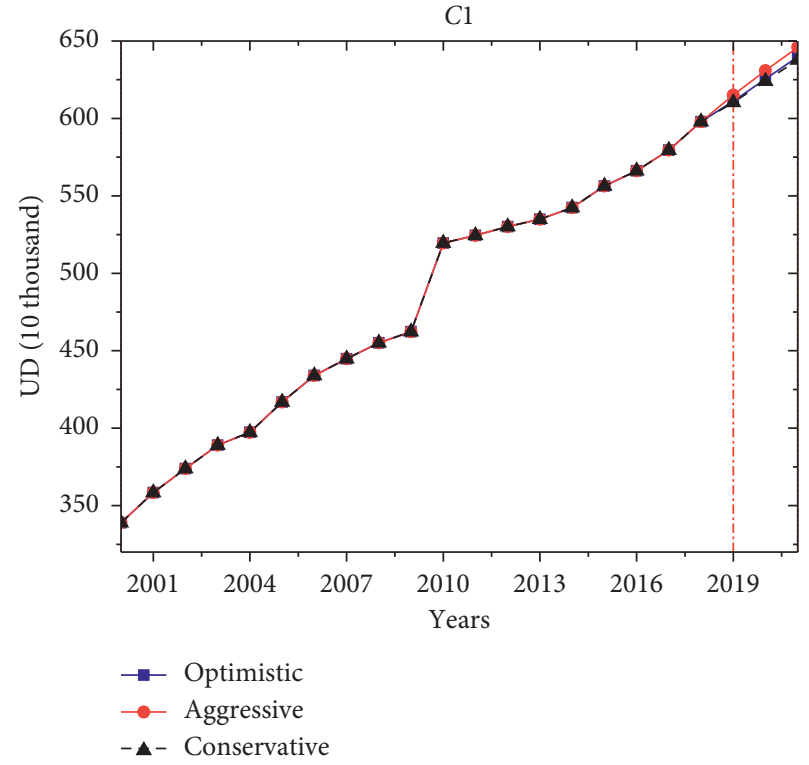

(a)

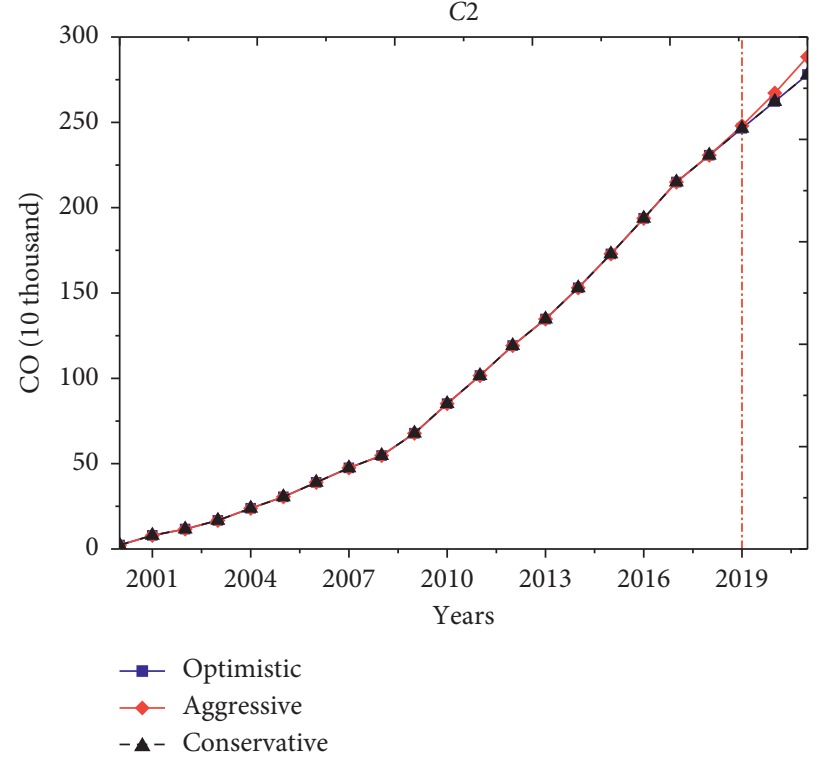

(b)

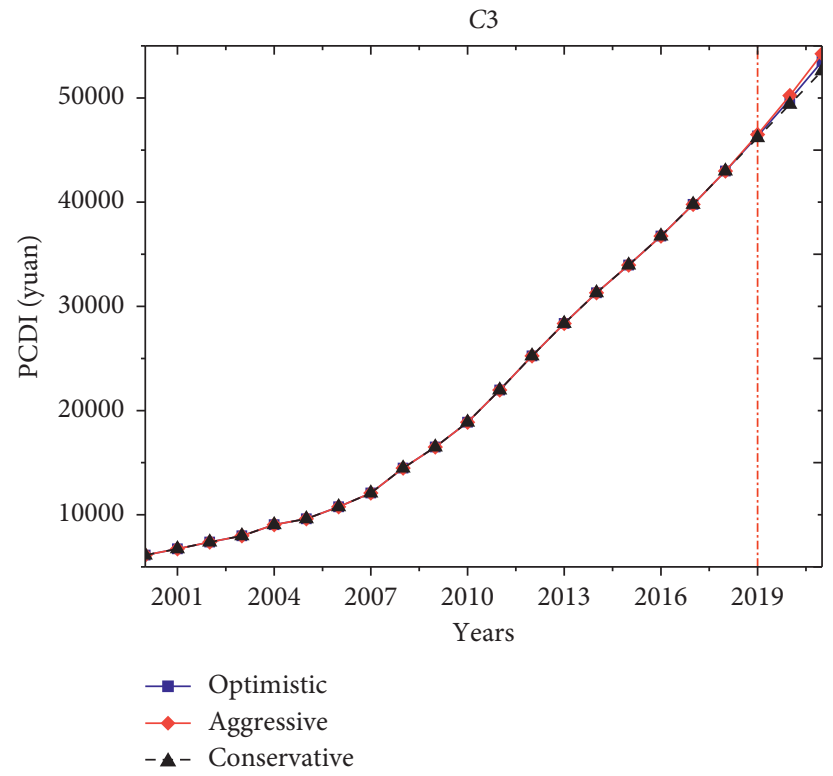

(c)

FiguRE 9: Future changes in the three data series for Kunming (2019-2021): (a) future changes in UD, (b) future changes in CO, and (c) future changes in PCDI.

conservative scenarios for the three cities is above 0.9 in all cases: the maximum is 0.999 and the minimum is 0.939 , which indicates that the data estimates obtained by the TSM are highly reliable. In terms of the level of goodness of fit, the conservative prediction is the highest, the optimistic prediction falls in the middle, and the aggressive prediction is the lowest, which is also consistent with the characteristics of the results shown in Table 13.

\section{Results}

The UD, CO, and PCDI data series for future years predicted by the three TSM models are substituted into the corresponding ternary quadratic equation presented in the first part of this paper. The $2 \mathrm{~h} \mathrm{CPP}$ in the core areas of NB, YC, and KM for the short term (2019-2021) and long term (2025, 2030) appear in Table 14. 
TABLE 8: Time series prediction for 2019-2021 (aggressive).

\begin{tabular}{|c|c|c|c|c|c|}
\hline Cities & Term & Year & UD (10 thousand) & CO (10 thousand) & PCDI (yuan) \\
\hline \multirow{5}{*}{ NB } & \multirow{3}{*}{ Short-term } & 2019 & 615.13 & 279.51 & 64730 \\
\hline & & 2020 & 630.91 & 306.19 & 69500 \\
\hline & & 2021 & 645.97 & 334.11 & 74463 \\
\hline & \multirow{2}{*}{ Long-term } & 2025 & 704.09 & 458.23 & 96252 \\
\hline & & 2030 & 775.97 & 641.38 & 127848 \\
\hline \multirow{5}{*}{ YC } & \multirow{3}{*}{ Short-term } & 2019 & 503.80 & 104.02 & 38967 \\
\hline & & 2020 & 511.02 & 114.21 & 42252 \\
\hline & & 2021 & 518.33 & 125.53 & 45800 \\
\hline & \multirow{2}{*}{ Long-term } & 2025 & 548.76 & 183.55 & 62991 \\
\hline & & 2030 & 590.91 & 278.32 & 92705 \\
\hline \multirow{5}{*}{ KM } & \multirow{3}{*}{ Short-term } & 2019 & 510.51 & 247.98 & 46496 \\
\hline & & 2020 & 525.06 & 267.18 & 50237 \\
\hline & & 2021 & 538.36 & 288.43 & 54244 \\
\hline & \multirow{2}{*}{ Long-term } & 2025 & 592.17 & 389.33 & 71951 \\
\hline & & 2030 & 661.89 & 535.62 & 97913 \\
\hline
\end{tabular}

Note. NB denotes Ningbo city, YC denotes Yancheng city, and KM denotes Kunming city.

TABLE 9: Time series prediction for 2019-2021 (conservative).

\begin{tabular}{|c|c|c|c|c|c|}
\hline Cities & Term & Year & UD (10 thousand) & CO (10 thousand) & PCDI (yuan) \\
\hline \multirow{5}{*}{ NB } & \multirow{3}{*}{ Short-term } & 2019 & 610.32 & 279.12 & 64454 \\
\hline & & 2020 & 624.05 & 304.24 & 68773 \\
\hline & & 2021 & 637.77 & 329.33 & 73093 \\
\hline & \multirow{2}{*}{ Long-term } & 2025 & 692.50 & 429.43 & 90369 \\
\hline & & 2030 & 760.62 & 554.00 & 111960 \\
\hline \multirow{5}{*}{$\mathrm{YC}$} & \multirow{3}{*}{ Short-term } & 2019 & 502.75 & 101.80 & 38664 \\
\hline & & 2020 & 508.67 & 111.86 & 41454 \\
\hline & & 2021 & 514.29 & 121.93 & 44243 \\
\hline & \multirow{2}{*}{ Long-term } & 2025 & 534.01 & 162.18 & 55398 \\
\hline & & 2030 & 553.45 & 212.48 & 69339 \\
\hline \multirow{5}{*}{ KM } & \multirow{3}{*}{ Short-term } & 2019 & 509.42 & 246.49 & 46179 \\
\hline & & 2020 & 519.80 & 262.22 & 49389 \\
\hline & & 2021 & 530.19 & 277.93 & 52600 \\
\hline & \multirow{2}{*}{ Long-term } & 2025 & 571.75 & 340.68 & 65442 \\
\hline & & 2030 & 623.69 & 418.85 & 81495 \\
\hline
\end{tabular}

Note. NB denotes Ningbo city, YC denotes Yancheng city, and KM denotes Kunming city.

TABLE 10: Comparison of the predicted and actual UD values (unit (10 thousand)).

\begin{tabular}{|c|c|c|c|c|c|}
\hline Cities & Type & Year & Predicted value & Actual value & Error (\%) \\
\hline \multirow{6}{*}{ Ningbo } & \multirow{2}{*}{ Optimistic } & 2017 & 583.11 & 579.56 & 0.613 \\
\hline & & 2018 & 595.29 & 597.93 & 0.442 \\
\hline & \multirow{2}{*}{ Aggressive } & 2017 & 589.24 & 579.56 & 1.670 \\
\hline & & 2018 & 601.22 & 597.93 & 0.550 \\
\hline & \multirow{2}{*}{ Conservative } & 2017 & 576.21 & 579.56 & 0.578 \\
\hline & & 2018 & 596.33 & 597.93 & 0.268 \\
\hline \multirow{6}{*}{ Yancheng } & \multirow{2}{*}{ Optimistic } & 2017 & 491.88 & 489.19 & 0.550 \\
\hline & & 2018 & 494.80 & 496.50 & 0.342 \\
\hline & \multirow{2}{*}{ Aggressive } & 2017 & 496.44 & 489.19 & 1.482 \\
\hline & & 2018 & 504.23 & 496.5 & 1.557 \\
\hline & \multirow{2}{*}{ Conservative } & 2017 & 484.17 & 489.19 & 1.026 \\
\hline & & 2018 & 493.22 & 496.5 & 0.661 \\
\hline \multirow{6}{*}{ Kunming } & \multirow{2}{*}{ Optimistic } & 2017 & 489.17 & 488.72 & 0.092 \\
\hline & & 2018 & 499.87 & 499.02 & 0.170 \\
\hline & \multirow{2}{*}{ Aggressive } & 2017 & 496.28 & 488.72 & 1.547 \\
\hline & & 2018 & 503.27 & 499.02 & 0.852 \\
\hline & \multirow{2}{*}{ Conservative } & 2017 & 484.32 & 488.72 & 0.900 \\
\hline & & 2018 & 498.21 & 499.02 & 0.162 \\
\hline
\end{tabular}


TABle 11: Comparison of the predicted and actual CO values (unit (10 thousand)).

\begin{tabular}{|c|c|c|c|c|c|}
\hline Cities & Type & Year & Predicted value & Actual value & Error (\%) \\
\hline \multirow{6}{*}{ Ningbo } & \multirow{2}{*}{ Optimistic } & 2017 & 226.82 & 229.00 & 0.010 \\
\hline & & 2018 & 253.43 & 254.00 & 0.002 \\
\hline & \multirow{2}{*}{ Aggressive } & 2017 & 232.41 & 229 & 1.489 \\
\hline & & 2018 & 259.34 & 254 & 2.102 \\
\hline & \multirow{2}{*}{ Conservative } & 2017 & 227.42 & 229 & 0.690 \\
\hline & & 2018 & 253.84 & 254 & 0.063 \\
\hline \multirow{6}{*}{ Yancheng } & \multirow{2}{*}{ Optimistic } & 2017 & 81.57 & 81.67 & 0.122 \\
\hline & & 2018 & 91.44 & 92.33 & 0.964 \\
\hline & \multirow{2}{*}{ Aggressive } & 2017 & 82.73 & 81.67 & 1.298 \\
\hline & & 2018 & 92.09 & 92.33 & 0.26 \\
\hline & \multirow{2}{*}{ Conservative } & 2017 & 80.11 & 81.67 & 1.910 \\
\hline & & 2018 & 92.07 & 92.33 & 0.282 \\
\hline \multirow{6}{*}{ Kunming } & \multirow{2}{*}{ Optimistic } & 2017 & 214.67 & 215.00 & 0.153 \\
\hline & & 2018 & 236.23 & 230.75 & 2.374 \\
\hline & \multirow{2}{*}{ Aggressive } & 2017 & 215.06 & 215 & 0.028 \\
\hline & & 2018 & 235.32 & 230.75 & 2.145 \\
\hline & \multirow{2}{*}{ Conservative } & 2017 & 213.21 & 215 & 0.833 \\
\hline & & 2018 & 228.07 & 230.75 & 1.161 \\
\hline
\end{tabular}

TABLE 12: Comparison of the predicted and actual PCDI values (unit (yuan)).

\begin{tabular}{|c|c|c|c|c|c|}
\hline Cities & Type & Year & Predicted value & Actual value & Error (\%) \\
\hline \multirow{6}{*}{ Ningbo } & \multirow{2}{*}{ Optimistic } & 2017 & 55178 & 55656 & 0.860 \\
\hline & & 2018 & 59609 & 60134 & 0.875 \\
\hline & \multirow{2}{*}{ Aggressive } & 2017 & 55785 & 55656 & 0.233 \\
\hline & & 2018 & 60824 & 60134 & 1.147 \\
\hline & \multirow{2}{*}{ Conservative } & 2017 & 55024 & 55656 & 1.136 \\
\hline & & 2018 & 58145 & 60134 & 3.308 \\
\hline \multirow{6}{*}{ Yancheng } & \multirow{2}{*}{ Optimistic } & 2017 & 32933 & 33115 & 0.550 \\
\hline & & 2018 & 35875 & 35896 & 0.059 \\
\hline & \multirow{2}{*}{ Aggressive } & 2017 & 33728 & 33115 & 1.851 \\
\hline & & 2018 & 36023 & 35896 & 0.354 \\
\hline & \multirow{2}{*}{ Conservative } & 2017 & 32909 & 33115 & 0.622 \\
\hline & & 2018 & 35372 & 35896 & 1.460 \\
\hline \multirow{6}{*}{ Kunming } & \multirow{2}{*}{ Optimistic } & 2017 & 39677 & 39788 & 0.279 \\
\hline & & 2018 & 42990 & 42988 & 0.005 \\
\hline & \multirow{2}{*}{ Aggressive } & 2017 & 39924 & 39788 & 0.342 \\
\hline & & 2018 & 43178 & 42988 & 0.442 \\
\hline & \multirow{2}{*}{ Conservative } & 2017 & 39542 & 39788 & 0.618 \\
\hline & & 2018 & 41372 & 42988 & 3.760 \\
\hline
\end{tabular}

TABLE 13: Testing the goodness of fit of the time series prediction results.

\begin{tabular}{lcccc}
\hline Types & Cities & UD & CO & PCDI \\
\hline \multirow{3}{*}{ Optimistic } & Ningbo & 0.980 & 0.992 & 0.994 \\
& Yancheng & 0.955 & 0.997 & 0.999 \\
\hline \multirow{3}{*}{ Aggressive } & Kunming & 0.969 & 0.999 & 0.962 \\
& Ningbo & 0.943 & 0.983 & 0.971 \\
\hline \multirow{3}{*}{ Conservative } & Yancheng & 0.951 & 0.939 & 0.986 \\
& Kunming & 0.958 & 0.985 & 0.994 \\
& Ningbo & 0.977 & 0.994 & 0.989 \\
\hline
\end{tabular}


TABLE 14: CPP prediction results.

\begin{tabular}{|c|c|c|c|c|c|}
\hline \multirow{2}{*}{ Cities } & \multirow{2}{*}{ Term } & \multirow{2}{*}{ Year } & \multicolumn{3}{|c|}{ CPP (yuan) } \\
\hline & & & Optimistic & Aggressive & Conservative \\
\hline \multirow{5}{*}{ Ningbo (NB) } & \multirow{3}{*}{ Short-term } & 2019 & 25.89 & 26.04 & 25.92 \\
\hline & & 2020 & 30.18 & 30.74 & 30.26 \\
\hline & & 2021 & 35.06 & 36.38 & 35.19 \\
\hline & \multirow{2}{*}{ Long-term } & 2025 & 60.56 & 70.65 & 60.79 \\
\hline & & 2030 & 105.23 & 149.64 & 105.86 \\
\hline \multirow{5}{*}{ Yancheng (YC) } & \multirow{3}{*}{ Short-term } & 2019 & 12.05 & 11.86 & 11.96 \\
\hline & & 2020 & 12.52 & 12.63 & 12.38 \\
\hline & & 2021 & 13.42 & 13.73 & 13.05 \\
\hline & \multirow{2}{*}{ Long-term } & 2025 & 21.07 & 23.98 & 18.32 \\
\hline & & 2030 & 43.97 & 62.15 & 31.12 \\
\hline \multirow{5}{*}{ Kunming (KM) } & \multirow{3}{*}{ Short-term } & 2019 & 21.68 & 21.99 & 21.58 \\
\hline & & 2020 & 26.36 & 27.3 & 26.05 \\
\hline & & 2021 & 31.63 & 33.89 & 30.94 \\
\hline & \multirow{2}{*}{ Long-term } & 2025 & 59.18 & 74.44 & 54.65 \\
\hline & & 2030 & 110.67 & 164.02 & 93.64 \\
\hline
\end{tabular}

TABLE 15: Results for the confidence intervals of three types of data in Ningbo (optimistic).

\begin{tabular}{lcccc}
\hline Year & Confidence interval & UD $(10$ thousand $)$ & CO (10 thousand) & PCDI (yuan) \\
\hline \multirow{2}{*}{2019} & Highest & 635.12 & 289.24 & 65827.4 \\
& Lowest & 587.26 & 268.49 & 63082.2 \\
\hline \multirow{2}{*}{2020} & Highest & 653.41 & 323.71 & 71483.7 \\
& Lowest & 597.60 & 283.79 & 66067.6 \\
\hline \multirow{2}{*}{2021} & Highest & 671.20 & 359.89 & 77362.5 \\
& Lowest & 608.44 & 297.38 & 68830.5 \\
\hline
\end{tabular}

TABle 16: The $2 \mathrm{~h}$ CPP range in the core area of Ningbo city in future years (optimistic).

\begin{tabular}{lc}
\hline Year & CPP range (yuan) \\
\hline 2019 & $(24.70,27.11)$ \\
2020 & $(27.36,33.26)$ \\
2021 & $(29.93,40.93)$ \\
\hline
\end{tabular}

\section{Discussion and Conclusion}

7.1. Discussion. According to the Goldilocks principle of [43], parking demand and supply are best balanced by setting the parking price appropriately. At present, the CPP in different cities in China is not the same, but it remains essential to balance demand and supply through price-setting [44]. On the basis of the research in this paper, parking pricing has a very high correlation with UD, CO, and PCDI. Therefore, the predicted development of the three data series can reflect the CPP in the core area of a city. This fact indicates that the research results in this paper have a certain predictive power.

This paper divides domestic cities into RCs, PCs, and TCs according to the differences in their parking fee systems and level of economic development. The $2 \mathrm{~h} \mathrm{CPP} \mathrm{data} \mathrm{for}$ almost all urban core areas, as well as the UD, CO, and PCDI data for most prefecture-level cities and above, were collected to fit the models. The final calculation results also reveal future changes in the $2 \mathrm{~h} \mathrm{CPP}$ of the urban core areas of Ningbo, Yancheng, and Kunming. Likewise, it would be possible to collect historical UD, CO, and PCDI data and then calculate the future CPP for other cities to which the model is fitted. For cities for which these data have not yet been collected, the model can be refitted to ensure that the ternary quadratic regression function is in accordance with the actual situation of the city, and then the CPP can be predicted after the parameters are modified.

As shown in Table 14, the CPP of the three cities of Ningbo, Yancheng, and Kunming shows a rapid growth trend predicted for the coming years. This is explained by the increases in UD, CO, and PCDI, which are also an inevitable result of accelerating urbanization. Among these variables, the increase in $\mathrm{CO}$ determines that the parking problem will continue to be an area of focus for policymakers in future years. Considering the combination of this increase and the current curb parking pricing policy adopted by most cities, the main problems are as follows:

(1) Parking demand that has not been effectively regulated [45]: the key principle for regulating parking demand is that off-street parking should be preferred over on-street parking; among the different types of off-street parking, indoor parking should be preferred as much as possible over open-air parking [46]. At present, most cities implement a time-based $\mathrm{CPP}$, divided into spells of less than $2 \mathrm{~h}$ and more than $2 \mathrm{~h}$. Generally, managers force parked cars to transfer to off-road parking after $2 \mathrm{~h}$ spells, so the 
unit parking fee for spells beyond $2 \mathrm{~h}$ is higher than that for spells under $2 \mathrm{~h}$. The CPPs in the core areas of Ningbo, Yancheng, and Kunming are low. Although the parking price of Ningbo is only 3 yuan, it is higher than that of the other two cities. This charging mechanism can neither effectively highlight the differences between on-street and off-street parking nor regulate the transfer of parked vehicles from on-street to off-street parking spaces.

(2) Pricing to encourage long-term parking [47]: the standard daytime CPP for parking spaces in 2017 is free parking for spells of less than $30 \mathrm{~min}$ and 2 yuan per 30 mins thereafter in Wanda Square, Ningbo, and the daytime parking fee per unit of time up to $12 \mathrm{~h}$ does not change. This price level is clearly within the tolerance of most urban residents because a car user pays only 51 yuan for $24 \mathrm{~h}$ of parking. Before the implementation of the intelligent parking project, the long-term parking utilization in this area was close to 50\%. There is a similar case in Ningbo city's Tianyi Square, where the current CPP standard is free parking for spells of up to $15 \mathrm{~min}$ and 3 yuan per 20 mins within $2 \mathrm{~h}$; this setup does not incentivize car users to transfer the vehicle to a car park because the fees for the first and second hours are the same. This situation is also common in Yancheng city, where the CPP is 1.5 yuan per 15 mins in the first-level area. In addition, the CPP in some cities decreases as the parking time increases; this is the case in Chengdu, which charges 10 yuan for the first hour of parking in the core area and 6 yuan for each hour thereafter up to a certain limit, which encourages long-term onstreet parking and restricts the development of high churn in on-street parking.

The CPP in the core area of Kunming is predicted to be 5.44 yuan higher than that of Ningbo in 2035, as seen in Table 12. In addition to the differences caused by the goodness of fit of the models for the RCs and TCs, Kunming's overall economic strength may be higher than that of Ningbo in future years.

In the past, when research has evaluated the current parking pricing problem, the final goal was always to obtain the optimal parking price [48-53]. We argue that the solution to the parking pricing problem should also consider the optimal parking price range, which spans the maximum value of the CPP that is acceptable to travelers and the minimum value of the CPP that is acceptable to decision makers. Similarly, the CPP problem is also likely to remain an issue in future years, so our findings can also be considered to obtain the CPP range for future years.

In this study, the confidence interval is set in the model fitting and variable prediction process (the confidence level is $95 \%)$. When the TSM is used to evaluate trends in UD, $\mathrm{CO}$, and PCDI, the output contains the results corresponding to the highest and lowest confidence levels for the three data series over future years. Examples of the predictions for the three data series in the optimistic TSM scenario for Ningbo city are shown in Table 15 .
By substituting the data in the above table into the nonlinear regression in sequence, the corresponding parking pricing fee interval for future years can be obtained, as shown in Table 16.

7.2. Conclusion. At present, the issue of imbalance between parking supply and demand for urban development is still a major challenge. It is of great practical importance to accurately determine the CPP for future years so as to quickly address the imbalance between parking supply and demand and provide theoretical support to decision makers.

The present study applied a TSM-RAM model to predict the CPP and solve the traffic problem caused by the imbalance between parking supply and demand. The data were obtained through the China Statistical Yearbook. The results showed the effectiveness of the TSM-RAM model for making parking price forecasts. At the same time, we paid special attention to dividing the results into optimistic, aggressive, and conservative estimates when applying the TSM to data series. In addition, the prediction of the curb parking price (CPP) was also based on the level of urbanization, with Chinese cities divided into RCs, PCs, and TCs, and case studies of Ningbo, Yancheng, and Kunming, which were selected as representative cities corresponding to each category. The diversity of the results also provides extra information to help policymakers respond to future parking problems.

The conclusion of this article can be attributed to the following three parts. Firstly, in terms of data, we found that the goodness-of-fit test results of the curb parking prices (CPP) and the number of urban dwellers (UD), car ownership (CO), and per capita disposable income of urban residents (PCDI) are all above 0.9 , indicating that the selected very high correlation between independent and dependent variables. Secondly, in terms of models and methods, we found that time series methods are used to predict the number of urban dwellers (UD), car ownership (CO), and per capita disposable income of urban residents (PCDI) results have extremely low errors, all of which are below 0.05 . Combining the three types of data with a very high degree of fit for on-street parking prices can prove that the TSM-RAM method is suitable for the CPP prediction. Finally, in terms of policies, we recommend regulating parking demand that off-street parking is encouraged between on-street parking and off-street parking; on the other hand, indoor parking is encouraged as much as possible between open-air parking and indoor parking for off-street parking and then determining prices that encourage shortterm parking.

However, there are some limitations to this study. First, the model in this paper only fits data for 36 RCs, 26 PCs, and 31 TCs. If sample data for more cities are properly added, the goodness of fit of the model could be improved. Second, this paper selects only three variables related to the CPP, namely, UD, CO, and PCDI. After researchers solve the difficult problems of data collection and prediction, factors such as road congestion can be added to the initial data to better improve the model fit and the accuracy of the model. 
Furthermore, extensions of this work should examine the categories of urban areas. This paper divides cities in China into RCs, PCs, and TCs according to their economic level, but it may also be a good choice to categorize cities according to their administrative level. This work has provided the framework for a TSM-RAM predictive curb parking price model. Under this framework, the curb parking price as affected by UD, CO, PCDI, or various other factors can be estimated to address parking problems in central urban districts.

In large cities, curb parking pricing (CPP) policies must differentiate parking charges by region. This article focuses on the selection of influencing factors of curb parking prices in core areas. Therefore, the article does not consider whether differentiated parking fees by region has an impact on curb parking pricing in a single region. This issue will be studied in detail in the next phase of the study by considering the impact of differentiated parking pricing policies on individual curb parking price.

In addition, the TSM-RAM method proposed in this paper has certain errors, but the results of the goodness-of-fit test, $T$-test, $F$ test, and error test are adequate, indicating that the error of the prediction result is within a reasonable range. Although a panel data model may have obvious advantages in recognizing measurement time series and cross-sectional data, describing individual behavioral differences, and constructing more complex behavioral models, there are also shortcomings related to the short time sequence and difficulties of variable design and data collection. Therefore, in the next step, we will conduct a panel data model study based on parking price research.

\section{Data Availability}

The data used to support the findings of this study are included within the article.

\section{Conflicts of Interest}

The authors declare that there are no conflicts of interest regarding the publication of this paper.

\section{Acknowledgments}

This research was funded by the Natural Science Foundation of Zhejiang Province (No. LQ19E080003), Philosophy and Social Science Program of Ningbo (G20-ZX07 and G20ZX37), the Natural Science Foundation of Ningbo (No. 2018A610127), the National Natural Science Foundation of China (No. 71861023), the Program of Humanities and Social Science of Education Ministry of China (No. 18YJC630118), and the Foundation of a Hundred Youth Talents Training Program of the Lanzhou Jiaotong University.

\section{References}

[1] T. Lin, G.-L. Lyu, F. Tian, and Y. Lu, "A pilot study of on-street parking charge in Shenzhen," Urban Transport of China, vol. 14, no. 4, pp. 30-39, 2016.
[2] China Statistical Bureau, Statistical Communique of National Economic and Social Development of China City, China Statistical Bureau, Beijing, China, 2000-2018, http://www.stats. gov.cn/tjsj/ndsj/.

[3] D. C. Shoup, "The ideal source of local public revenue," Regional Science and Urban Economics, vol. 34, no. 6, pp. 753-784, 2004.

[4] Y. Guo, A. Osama, and T. Sayed, "A cross-comparison of different techniques for modeling macro-level cyclist crashes," Accident Analysis \& Prevention, vol. 113, pp. 38-46, 2018.

[5] P. A. Barter, "Off-street parking policy surprises in Asian cities," Cities, vol. 29, no. 1, pp. 23-31, 2012.

[6] Z.-S. Yang and X.-D. Chen, "Research on the estimation for effective parking space of the intelligentized parking guidance system," Journal of Transportation Systems Engineering and Information Technology, vol. 3, no. 4, pp. 12-15, 2003.

[7] A. Mondschein, D. A. King, C. Hoehne, Z. Jiang, and M. Chester, "Using social media to evaluate associations between parking supply and parking sentiment," Transportation Research Interdisciplinary Perspectives, vol. 4, pp. 100085-100088, 2020.

[8] T. Rye, T. Cowan, and S. Ison, "Expansion of a controlled parking zone (CPZ) and its influence on modal split: the case of Edinburgh," Transportation Planning and Technology, vol. 29, no. 1, pp. 75-89, 2006.

[9] F. Kirschner and M. Lanzendorf, "Parking management for promoting sustainable transport in urban neighbourhoods. A review of existing policies and challenges from a German perspective," Transport Reviews, vol. 40, no. 1, pp. 54-75, 2020.

[10] Z. Zhao, Y. Zhang, and Y. Zhang, "A comparative study of parking occupancy prediction methods considering parking type and parking scale," Journal of Advanced Transportation, vol. 2020, no. 10, 12 pages, 2020.

[11] C. Ma, W. Hao, A. Wang, and H. Zhao, "Developing a coordinated signal control system for urban ring road under the vehicle-infrastructure connected environment," IEEE Access, vol. 6, pp. 52471-52478, 2018.

[12] W.-D. Middleton, “Transportation for livable cities," Railway Age, vol. 30, pp. 1-10, 2000.

[13] G. Marsden, "The evidence base for parking policies-a review," Transport Policy, vol. 13, no. 6, pp. 447-457, 2006.

[14] D. Shoup, "The price of parking on a great street," Parking Today, vol. 14, no. 2, pp. 22-23, 2006.

[15] T. Litman, "Pricing for traffic safety: how efficient transport pricing can reduce roadway crash risk," Transportation Research Record Journal of the Transportation Research Board, vol. 8, no. 2318, pp. 16-22, 2012.

[16] N. Terui and H. K. Van Dijk, "Combined forecasts from linear and nonlinear time series models," International Journal of Forecasting, vol. 18, no. 3, pp. 421-438, 2002.

[17] W.-G. Xiao and X.-M. Lan, "Research on the nonlinear mechanism of the influence of the RMB exchange rate expectation on real estate price in China," Soft Science, vol. 31, no. 12, pp. 129-133, 2017.

[18] H. Yin, Z.-G. Li, Y.-L. Wang, and F. Cai, "Assessment of desertification using time series analysis of hyper-temporal vegetation indicator in inner Mongolia," Acta Geographica Sinica, vol. 66, no. 5, pp. 653-661, 2011.

[19] X.-B. Huang, H.-B. Li, Y.-C. Zhu, Y.-X. Wang, X.-X. Zhang, and Y.-G. Wang, "Short-term forecast for transmission line icing by time series analysis and kalman filtering," High Voltage Engineering, vol. 43, no. 6, pp. 1943-1949, 2017. 
[20] Z.-Y. Zhu, "Time series analysis of Chinese insurance compensation-modeling and forecasting," Journal of Applied Statistics and Management, vol. 29, no. 4, pp. 698-704, 2010.

[21] N. Rabindra and P. Nirash, "A multivariate time series analysis of energy consumption, real output and pollutant emissions in a developing economy: new evidence from Nepal," Economic Modeling, vol. 77, pp. 164-173, 2019.

[22] H. Reiser and H. Kutie, "Rainfall uncertainty in the Mediterranean: time series, uncertainty, and extreme events," Theoretical and Applied Climatology, vol. 104, no. 3-4, pp. 357-375, 2011.

[23] M. Ding, L.-J. Zhang, and Y.-C. Wu, "Wind speed forecast model for wind farms based on times series analysis," Electric Power Automation Equipment, vol. 25, no. 8, pp. 32-34, 2005.

[24] R. E. Abdelaal and A. Z. Algarni, "Forecasting monthly electric energy consumption in eastern Saudi Arabia using univariate time-series analysis," Energy, vol. 22, no. 11, pp. 1059-1069, 2014.

[25] J. Hu, J.-G. Lin, and Y.-Y. Zhao, "The influence of generalized linear model based on the pena distance," Mathematica Applicata, vol. 30, no. 3, pp. 539-546, 2017.

[26] Z.-H. Wang, G.-Y. Shan, and Y.-W. Lin, “"Multi-linear regression analysis using Microsoft excel and it's application in Chemistry," Computers and Applied Chemistry, vol. 22, no. 9, pp. 121-124, 2005.

[27] H. Sun, Z.-M. Zhang, and H.-J. Ge, "Application of PSO to improve multiple linear regression," Computer Engineering and Applications, vol. 43, no. 3, pp. 43-44, 2007.

[28] H. Zhou, C.-W. Jiang, W. Fang, M.-W. Liang, J.-W. Huang, and T.-Y. Hou, "Verification for performance of anti-dsDNA antibody quantitative ELISA kit," Chinese Journal of Clinical Laboratory Science, vol. 35, no. 7, pp. 533-537, 2017.

[29] B. Lin, "Multiple linear regression analysis and its application," China Science and Technology Information, vol. 9, no. 3969, pp. 60-61, 2010.

[30] M. Val, Y. Shih-Cheng, T. Arthur et al., "Regression analysis of gait parameters and mobility measures in a healthy cohort for subject-specific normative values," PLoS One, vol. 13, no. 6, Article ID e0199215, 2018.

[31] Q.-B. Yu, D. Su, Z.-J. Jiao, and C. Li, "Enhancement of near infrared spectroscopy determination of water contents in oils using oil-water stabilization and support vector regression," Chinese Journal of Analytical Chemistry, vol. 42, no. 9, pp. 1364-1368, 2014.

[32] H. Kaneko, M. Arakawa, and K. Funatsu, "Development of a new regression analysis method using independent component analysis," Journal of Chemical Information and Modeling, vol. 48, no. 3, pp. 534-541, 2008.

[33] D. Liu, J.-D. Zhai, and W.-G. Chen, "A regression-based predication model for tpc-c performance of high-end faulttolerant computer," Chinese Journal of Computers, vol. 36, no. 6, pp. 1267-1279, 2013.

[34] F. Peng, D.-L. Zhou, M. Long, and X.-M. Sun, "Discrimination of natural images and computer generated graphics based on multi-fractal and regression analysis," $A E U$ -International Journal of Electronics and Communications, vol. 71, pp. 72-81, 2017.

[35] Y. Ma, Q. Wang, Z. Chen et al., "Multiple linear regression analysis of X-ray measurement and WOMAC scores of knee osteoarthritis," China Journal of Orthopaedics and Traumatology, vol. 25, no. 2, pp. 373-376, 2012.

[36] T. Kondo, J. Ueno, and S. Takao, "Logistic GMDH-type neural network using principal component-regression analysis and its application to medical image diagnosis of lung cancer," Artificial Life and Robotics, vol. 20, no. 2, pp. 137-144, 2015.

[37] J. Qu and X. Chen, "Study of curb parking price in Chengdu," Journal of Transportation Engineering and Information, vol. 10, no. 1, pp. 111-114, 2012.

[38] J. A. Kelly and J. P. Clinch, "Influence of varied parking tariffs on parking occupancy levels by trip purpose," Transport Policy, vol. 13, no. 6, pp. 487-495, 2006.

[39] D. Albalate and A. Gragera, "The determinants of garage prices and their interaction with curbside regulation," Transportation Research Part A: Policy and Practice, vol. 101, pp. 86-97, 2017.

[40] M. B. W. Kobus, E. Gutiérrez-i-Puigarnau, P. Rietveld, and J. N. Van Ommeren, "The on-street parking premium and car drivers' choice between street and garage parking," Regional Science and Urban Economics, vol. 43, no. 2, pp. 395-403, 2013.

[41] X. Huang, "Remodeling and adjustment: study on county floating population identity in the process of new urbanization," Journal of Ningbo Radio \& Tv University, vol. 15, no. 1, pp. 22-27, 2017.

[42] X. Mao, C. Yuan, J. Gan, and J. Zhou, "Optimal evacuation strategy for parking lots considering the dynamic background traffic flows," International Journal of Environmental Research and Public Health, vol. 16, no. 12, pp. 2194-2205, 2019.

[43] T. Rye, The Implementation and Effectiveness of Transport Demand Management Measures: An International Perspective, Rout Ledge: Taylor \& Francis Group, Abingdon, UK, 2016.

[44] Y.-Y. Guo, P. Liu, Y. Wu, and J.-X. Chen, "Evaluating how right-turn treatments affect right-turn-on-red conflicts at signalized intersections," Journal of Transportation Safety \& Security, vol. 12, no. 3, pp. 1-38, 2018.

[45] M.-C. He, J.-H. He, J.-L. Li, and Y. Li, "Curb parking pricing model based on time series and regression analysis," Journal of Transportation Engineering and Information, vol. 16, no. 1, pp. 79-84, 2018.

[46] C.-X. Ma, W. Hao, R.-C. He et al., "Distribution path robust optimization of electric vehicle with multiple distribution centers," PLoS One, vol. 13, no. 3, pp. 1-16, 2018.

[47] Z. Wang, "An important carrier for building urban business center," Ningbo Communications, vol. 18, no. 2, pp. 46-47, 2012.

[48] A. Filipovitch and E. Frimpong Boamah, "A systems model for achieving optimum parking efficiency on campus: the case of Minnesota State University," Transport Policy, vol. 45, pp. 86-98, 2016.

[49] Y. Guo, T. Sayed, and M. H. Zaki, "Evaluating the safety impacts of powered two wheelers on a shared roadway in China using automated video analysis," Journal of Transportation Safety \& Security, vol. 11, no. 4, pp. 414-429, 2019.

[50] Y. Guo, Z. Li, P. Liu, and Y. Wu, "Modeling correlation and heterogeneity in crash rates by collision types using full Bayesian random parameters multivariate Tobit model," Accident Analysis \& Prevention, vol. 128, pp. 164-174, 2019.

[51] Y. Guo, L. Zheng, and T. Sayed, "A comparison of collisionbased and conflict-based safety evaluation of left-turn bay extension," Transportmetrica A: Transport Science, vol. 16, no. 3, pp. 676-694, 2020.

[52] Y.-Y. Guo, P. Liu, Y. Wu, and M.-L. Yang, "Traffic conflict model based on bayesian multivariate Poisson-lognormal normal distribution," China Journal of Highway and Transport, vol. 31, no. 1, pp. 101-109, 2018.

[53] G. Antolín, B. Alonso, and R. Cordera, "The effect of introducing parking policies on managing mobility to beaches in touristic coastal towns," Sustainability, vol. 11, no. 3528, pp. 1-13, 2019. 